\title{
COMPORTAMENTO DE FOSFATOS SILICATADOS \\ EM SOLO DE CERRADO
}

\author{
MINORU YASUDA
}

Engenheiro Agrōnomo

Orientador: Prof. Dr. TOSHIARI RINJO

Dissertação apresentada à Escola Superior de Agricul tura "Luiz de Queiroz", da Universidade de São Paulo, para obtenção do título de Mestre em Agronomia. Área de concentração: Solos e Nutrição de plantas.

\author{
PIRACICABA \\ Estado de São Paulo - Brasil \\ Novembro - 1989
}


Ficha catalográfica preparada pela Seção de Livros da Divisāo de Biblioteca e Documentação - PCAP/USP

Yasuda, Minoru

Y29c Comportamento de fosfatos silicatados em solo de cerrado. Piracicaba, 1989.

$62 \mathrm{p}$.

Diss. (Mestre) - ESALQ

Bibliografia.

1. Cerrado - Solo 2. Fosfato silicatado em solo Comportamento 3. Fósforo em solo - Disponibilidade 4. Latossolo vermelho-escuro álico 5. Silício em so 10 6. Solo - Acidez 7. Solo - Fertilidade I. Escola Superior de Agricultura Luiz de Queiroz, Piracicaba CDD 631.42 
COMPORTAMENTO DE FOSFATOS SILICATADOS EM SOLO DE CERRADO.

MINORU YASUDA

Aprovada em: $13 / 12 / 1989$

Comissão Julgadora:

Prof.Dr. Toshiaki Kinjo

ESALQ/USP

Prof.Dr. Ronaldo Ivan Silveira

ESALQ/USP

Prof.Dr. Takashi Muraoka

CENA

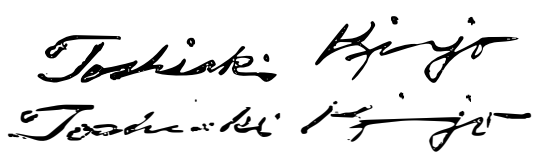

Prof.Dr. Toshiaki Kinjo

Orientador 
IEsta Tese é dedicada

a mima esposa cecitia,

pelo apoio e compreensão.

$E$ aos meus filhos, Gustavo

e Thais Helena.

A memōria do meu pai, minha mãe e meus irnãos

ofereço. 


\section{AGRADECIMENTOS}

Ao Professor Toshiaki Kinjo pela orientação, confiança e sugestões para o bom desenvolvimento deste trabalho.

Ao Professor Leonardo Theodoro Bull e ao Professor Júlio Nakagawa pela colaboração prestada na execução deste trabalho.

À Escola Superior de Agricultura "Luiz de Queiroz" (ESALQ/ USP) pela oportunidade proporcionada para realização do curso de mestrado, e ao CAPES (Coordenação do Aperfeiçoamento de (Pessoal de Nivel Superior) pelo auxilio financeiro da parte dos recursos utilizados.

Ao Professor Takashi Muraoka, pesquisador do Centro de Energia Nuclear na Agricultura (CENA), ao Dr. Tsuioshi Yamada, Di retor da Potafós, pelas valiosas sugestões e especial atenção.

A Fertilizantes Mitsui S.A. Ind. e Com., pelo apoio, in centivo e pela possibilidade de realização do Curso de Pós-Graduạ̧ã̃o:

Aos Amigos da seção técnica agrícola - Mitsui pela ajuda e convívio.

A todos que, direta ou indiretamente, contribuiram para a realização deste trabalho. 


\section{SUMÁRIO}

Página

RESUMO.............................. vi

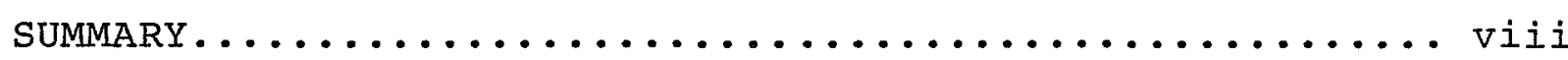

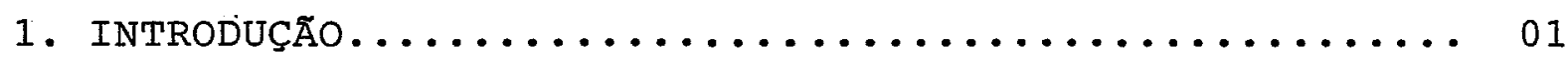

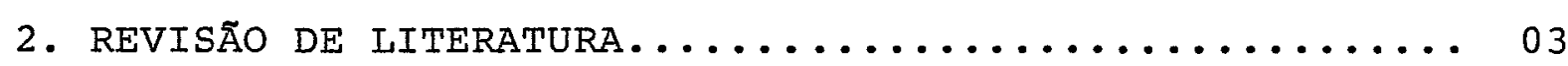

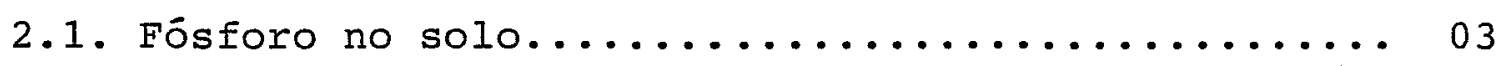

2.2. Silicio no solo e efeitos sobre plantas......... 04

2.3. Interação entre silício e o fósforo........... 09

2.4. Termofosfato magnesiano e seu emprego na agricultura............................... 14

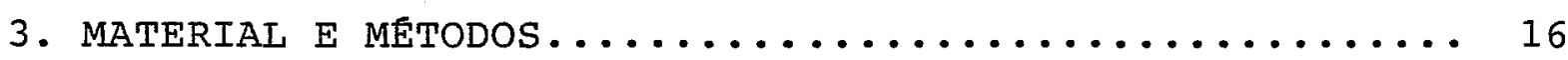

3.1. Localização dos ensaios.................. 16

3.2. Solo utilizado...................... 16

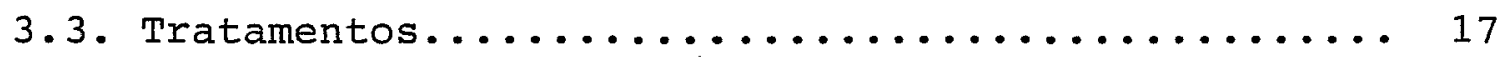

3.4. Ensaios em cada vegetação................. 19

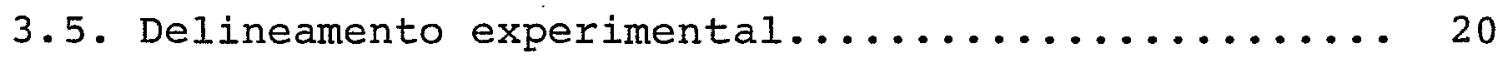

3.6. Análise química de solo após a incubação....... 20

3.7. Análise química do material vegetal.......... 21

3.8. Análise estatistica................... 21

4. RESUltados E DISCUSSÃo

4.1. Fósforo solūvel, bases trocáveis e acidez do solo 22 4.1.1. P solúvel em $\mathrm{H}_{2} \mathrm{SO}_{4} 0,05 \cdot \mathrm{N}$ e extraivel em

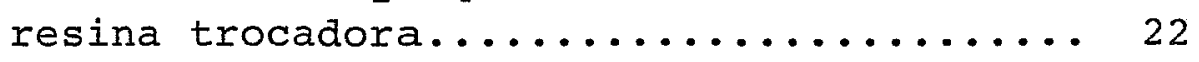

4.1.2. $\mathrm{Ca}^{2+}$ e $\mathrm{Mq}^{2+}$ trocáveis.............. 28

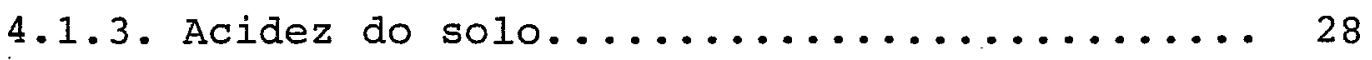

4.2. Produção de matēria seca, absorção de $P$ e bases

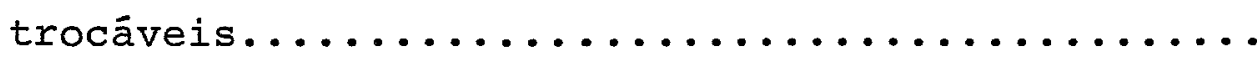


4.2.1. Produção de matéria seca............ 37

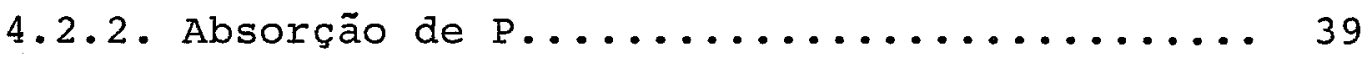

4.2.3. Absorção de $\mathrm{Ca}^{+2}, \mathrm{Mg}^{+2}$ e $\mathrm{K}^{+} \ldots \ldots \ldots \ldots \ldots . . .44$

5. CONCLUSÕES........................... 52

BIBLIOGRAFIA CITADA...................... 53 


\section{COMPORTAMENTO DE FOSFATOS SILICATADOS \\ EM SOLO DE CERRADO}

Autor: MINORU YASUDA

Orientador: TOSHIAKI KINJO

\section{RESUMO}

Este trabalho teve como objetivo estudar os fos fatos silicatados na disponibilidade do fósforo em um Latossolo Vermelho Escuro-älico (LEa), classe textural franco argilo-arenoso da Fazenda Experimental Lageado da Faculdade de Ciências Agronômicas, UNESP, Campus de Botucatu.

o experimento foi desenvolvido em casa-de-vege tação no Departamento de Ciências do Solo da Faculdade, em vasos cerâmicos com capacidade de 5 litros, utilizando-se alface como planta teste.

Foram utilizados três fontes fosfata dos: . YOORIÑ (YO), YOOSIRIN (YS) e TRIPLO (ST), em "quantidades equivalentes a 150 ppm, avaliando-se 7 épocas diferentes de incubação espaçados de 15 dias.

Conclui-se que o fosfatado de maior teor de sí 
lica, YS apresentou os maiores teores de fósforo disponivel no solo e proporcionou maiores valores de $\mathrm{pH}$.

As produções de matéria seca obtidas com a aplicação das três fontes diferiram entre si, sendo que o Yoosirin proporcionou maior produção que Yoorin e este suplantou o superfosfato Triplo. 


\section{BEHAVIOR OF SILICATED PHOSPHATES}

IN CERRADO SOIL

Author: MINORU YASUDA

Adviser: TOSHIAKI KINJO

\section{SUMMARY}

The purpose of this work was to study the influence of silicated phosphates on some chemical properties of soil and on plant growth. The soil sample was collected from the Sandy Dark Red Iatosol located at Experiment: was carried out in greenhouse, using pots of 5 liter capacity and lettuce as test plant. The treatments consisted of three phosphorus sources, namely two magnesium thermophosphates YOORIN (YO), YOOSIRIN (YS) and triple superphosphate for comparison. . The amount of 150 ppm phosphorus was applied to the soil samples which were incubated at seven different periods, spaced 15 days from one to another period. It is concluded that treatment with the phosphate containing the largest amount of silicon YS, showed, the highest value of $\mathrm{pH}$ and available phosphorus in the soil. The dry matter production obtained by the use of the three phosphorus sources were statistically different. Yoosirin produced more than Yoorin and the latter more than triple superphosphate. 


\section{INTRODUÇÃO}

Com o substancial aumento de taxa de crescimen to de produção agrícola brasileira nas ültimas décadas, vem diminuindo a disponibilidade de áreas de cultivos tradicionais, normalmente mais férteis, principalmente nos Estados do sul e sudeste, chegando à necessidade do aumento da fronteira agricola, dispondo-se como grande opção, a região dos cerrados. Cerca de 1,8 milhões de $\mathrm{Km}^{2}$ ou seja $20 \%$ do território brasileiro, estendendo-se principalmente pela região. Centro-Oeste e abrangendo parte da região Norte, Nordeste e Sudeste (EMBRAPA, 1978).

As āreas sob vegetação de cerrado apresentam topografia em geral, adequada a expansão de uma agricultura mais avançada, mas um dos fatores limitantes para o crescimento agricola deve ser os baixos niveis de quase todos os nutrientes essenciais para as plantas. Inicialmente abrigava uma pecuária extensiva e de baixa produtividade, que subsistia extraindo-se carvão vegetal. Aos poucos foram implantado também projetos de reflorestamento e pastagens melhoradas, aproveitando-se de incentivos governamentais surgi dos na época. 
Atualmente pode-se afirmar que a região dos cer rados representa a curto e médio prazo, a grande opção brasị leira para sustentação de indispensáveis e altos níveis de crescimento agricola, desde que sejam corrigidas as deficiên cias generalizadas de nutrientese elevada acidez dos solos. Dentre os vários problemas nutricionais destes solos, ocupa lugar de destaque a baixa disponibilidade natural de fósforo ea altacapacidade de "fixação" deste nutriente, fazendo com que tenham uma baixa eficiência para as culturas quando não são adequadamente manejadas.

A calagem adequada pode proporcionar diminuição da fixação de fósforo. Alguns trabalhos têm demonstrado tambēm o efeito positivo do silício no comportamento do fósforo em solos com alta capacidade de fixação. Este efeito po de ser devido principalmente ao aumento do aproveitamento de fósforo pela elevação do pH, e competição de silicato com fos fato, pelos mesmos sitios de adsorção (HINGSTON et alii, 1968). Se forem constatados esses efeitos benéficos de silicio, na utilização desses fertilizantes fosfatados, de reação alcalina, poderá tornar a adubação fosfatada mais eficiente.

Nesse sentido, conduziu-se o presente trabalho com o objetivo de avaliar o efeito da combinação (fósforo silicato) na disponibilidade de fósforo em solo com alta capacidade de fixação deste nutriente. 


\section{REVISÃO DE LITERATURA}

\subsection{Fósforo no solo}

O fósforo è um dos macronutrientes importante, possuindo um comportamento peculiar no solo.

Ao estudar o fósforo, é necessário conhecer a forte interação com o solo, aliada à carência generalizada deste elemento nos solos brasileiros.

A sua dinâmica no solo pode ser esquematizada como segue (Larsen, 1971; citado por VOLKWEISS \& RAIJ, 1976)

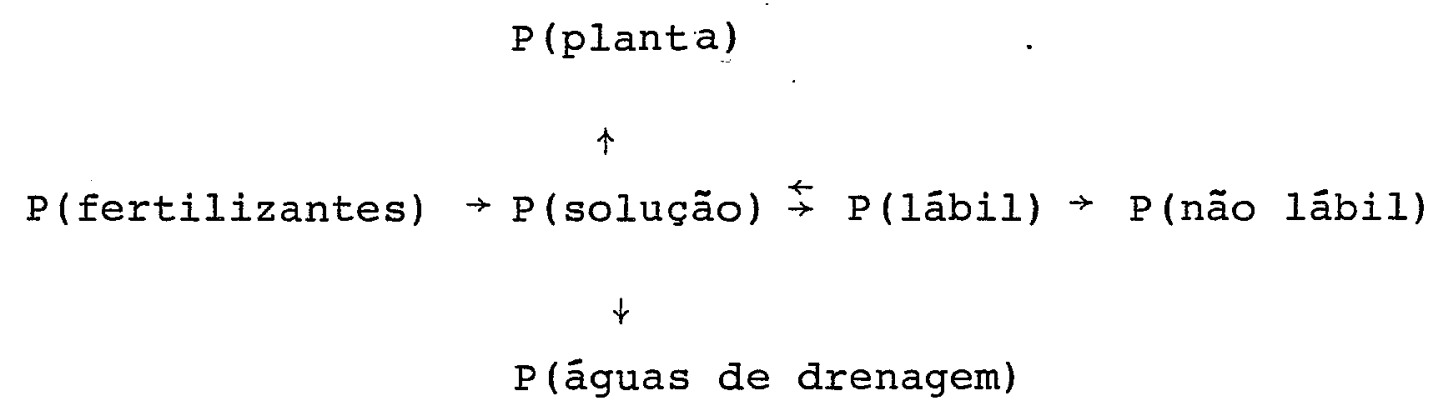

Esta representação mostra que as plantas absorvem o fósforo da solução do solo, que está em equilíbrio com o chamado fósforo lábil.

A adição de fertilizantes fosfatados, princi- 
palmente solúveis, altera o equilibrio das formas de fósforo, aumentando rapidamente o P(solução), e o fósforo lábil que é disponível para as plantas. E com o tempo o fósforo lábil vai transformando-se gradativamente em fósforo não lábil que cons titui o fósforo imobilizado.

o P-lābil entra em equilíbrio mais ou menos rá pido com o P da solução e o P não lābil entra em equilíbrio mais lentamente. O conjunto constitui o P-sólido(VOLKWEIss \& RAIJ, 1976) .

A "fixação" parcial como p-lábil e total como P-não lábil é explicada pelo mecanismo de adsorção dos ions fosfato junto às superfícies de óxidos de aluminio e ferro predominantes nos solos de características ácidas, como, em geral são os solos de cerrados. Uma vez adsorvidos, passamse à cristalização. Inicialmente, formam-se compostos amorfos e coloidais que podem passar a cristalinos, fixando=se de um mo do total se ficarem oclusos. A combinação Fe-P cristaliza mais rapidamente que a combinação $A l-P$, e sob forma cristali na, sua disponibilidade para as plantas torna-se muito baixa.

\subsection{Silicio no solo e efeitos sobre plantas}

o silício é um dos elementos mais abundantes na crosta terrestre, ocorrendo principalmente na forma de si licatos e quartzo. 
Os teores totais de silicio na fração argila diminui com o grau de intemperismo. o aumento de intensidade do intemperismo provoca maior alteração dos minerais primários, com a consequente perda dos elementos mais solúveis ( $\mathrm{Ca}, \mathrm{Mg}, \mathrm{Na}, \mathrm{K}$, etc.) e uma posterior dessilicação desses mị nerais. Este é o processo de formação de solos latossólicos, que possuem como minerais predominantes argilas cauliniticas, óxidos e hidróxidos de Fe e Al.

RODRIGUES (1977), observou em oxissolos do Bra sil Central, que os teores de aluminossilicatos amorfos variam de 5 a 19\%. Estes valores foram mais elevados nos horizontes superficiais, decrescendo com a profundidade. Segundo Chwewtmann et alii citado por RODRIGUES (1977), isto ocorre porque os compostos orgânicos podem reter os óxidos de $\mathrm{Fe} e$ Al amorfos, retardando a sua cristalização.

o teor de silício na solução dos solos é resul tante da solubilidade dos compostos sólidos contendo silício, presente no solo. Assim, a concentração de silica na solução dos solos deve ser bastante variável. CASTRo (1975), cita valores menores que 1 a mais de $20 \mathrm{ppm}$ de $\mathrm{SiO}_{2}$.

RAIJ \& CAMARGO (1973), constataram que os teores de silica extraível com $\mathrm{CaCl}_{2} 0,0025 \mathrm{M}$, variaram de 2,2 a $92,2 \mathrm{ppm}$ do $\mathrm{SiO}_{2}$ e que os valores maiores encontrados nos solos mais argilosos, havendo também uma relação de intemperis mo. Para os solos com os mesmos teores de argila, os teores de silica solúvel foram maiores nos solos com horizonte $B$ la tossólico. 
HINGSTON et alii (1968, 1972), observaram que a máxima adsorção de silicato por gibbsita e goetita ocorre em $\mathrm{pH}$ próximo do $\mathrm{pKa}_{1}(9,6)$ do ácido silícico, sendo menor em pH baixo e mais altos. MCKEAGUE \& CLINE (1963) pesquisaram muitas substâncias com capacidade de remover $\mathrm{Si}$ da solução; hematita e goetita mostram adsorção moderada, minerais silicatados e solo alcalino carbonatado apresentam pequena ou nenhuma capacidade de adsorver Si.

o silício não è reconhecido como elemento essencial às plantas, faltando ainda informações na ārea de ação bioquimica, sendo este, talvez, o motivo pelo qual não desperta muito interesse para os pesquisadores. A literatura interhacional mostra resultados de trabalhos sobre a ação do Si no desenvolvimento e na produção de algumas culturas.

Frey Wyssling, citado por JONES \& HANDRECK (1967) relata que o silício é absorvido pelas gramineas através do fluxo de massa por processo não seletivo. O silicio absorvido acumula-se nas células epidérmicas, aparentemente proporcionando uma certa resistência às doenças. Segundo JONES \& HANDRECK (1977), quase a metade do total de silica da parte aérea se localiza nas inflorescēncias, e o resto se distribui entre as folhas e os colmos.

A maior parte do silicio encontra-se nas plan tas na forma inorgânica e pequena parte em combinação como proteína nas plantas superiores lOzaki \& Higashiro, citados por OKUDA \& TAKAHASHI, 1964). Grossebrauckmann citado por Jo 
NES \& HANDRECK (1967), comparando gramineas e leguminosas em solo húmico arenoso de $\mathrm{pH}$ 5,2 encontrou valores de 1,95 e $1,58 \%$ de $\mathrm{SiO}_{2}$ em cevada e centeio, ao passo que no trevo ver melho, tremoço azul havia somente 0,12 e $0,24 \%$ de $\mathrm{SiO}_{2}$ respectivamente.

Em plantas ricas em silicio, inclusive o arroz, as concentrações chegam até $0 \%$ Geralmente, tecidos mais velhos da planta contềm maior teor de silício do que os mais jovens. Conforme MENGEL \& KIRKBY (1982) os cereais e as gramineas contêm de ${ }^{\cdots} 0,2$ a $2 \%$ na de matéria seca, enquanto que as dicotiledôneas podem conter apenas um décimo desta quantidade ou menos.

HALAIS \& PARISH (1963), constataram que a absorção de silício aplicado no solo está relacionada ao teor de óxido de $\mathrm{Fe}$ e de Al. Embora as espécies sejam diferentes na capacidade em absorver silício na solução de solo è a mes ma encontrada na planta (Fox et alii, 1967, citado por HALAIS \& PARISH, 1963). CLEMENTS (1967). observou que a aplicação de silício causou uma redução significativa de manganês na planta e admitiu que um dos efeitos do silicato consiste na redução dos efeitos tóxicos do manganês, cobre, ferro e de outros.

O silício é necessário à cultura de arroz pelas suas peculiaridades fisiológicas, atuando todo o periodo de desenvolvimento da planta e na formação do grão, segundo OKUDA \& TAKAHASHI (1964). LEWIN \& REIMANN (1969), destacam a 
importância do silício nas plantas, na fertilidade do solo e na resistência ao ataque de pragas e doenças.

A função especifica do silício nas plantas é pouco conhecida, mas a presença deste elemento na cana-de-açúcar em quantidades variáveis foi constatado por HUSz (1972). Ainda que o silicio seja normalmente abundante, alguns solos são deficientes. A aplicação de silicatos em solos do Havaí é feita em quantidades maiores do que 7 toneladas por hectare. Conforme RAUPACK \& PIPPER (1959) a produtividade da cana-de-açúcar foi significativamente aumentada com a aplicação de silicatos em duas variedades de cana-de-açúcar, tendo os efeitos desaparecidos com a soqueira. A baixa produção de cana-de-açúcar foi melhorada pela aplicaçaõ de 7 a 17 tonela das de silicato de cálcio por hectare no plantio.

A concentração de silicio na solução do solo foi diminuida na presença de carbonato de cálcio, reduzindo deste elemento pela cana-de-açúcar, AYRES (1966). Por outro lado, o silicato de cálcio foi responsável pelo aumento do pH do solo e diminuição de manganēs e aluminio. Este pesquisador propôs que algum nivel de disponibilidade de silício no solo deve existir, o qual é essencial para o crescimento normal da cana-de-açúcar. Segundo BAIR (1966), o teor de silício na folha foi mais elevado em plantas crescendo em solos de alta produtividade do Havaí e para algumas áreas de baixa produtividade o teor de silício estava abaixo do nivel limitante de produção de cana-de-açúcar. … Fox ... et alii 
citado por BAIR (1966), sugerem que o silício solúvel pode fornecer suficiente informação sobre o teor do elemento na planta, sendo este maior na bainha que nas folhas de cana-de -açúcar. Constataram ainda que, embora os compostos solúveis de silicio em tecido de cana-de-açúcar não sejam abundantes, ele se encontra em maior concentração nos tecidos menos ativos metabolicamente e também com elevado teor de fósforo. Yo SHIDA (1982) et alii estuđaram novo método para determinação da localização da silica nos tecidos das plantas de reação com ácido hidrofluoridrịco everificaram a possibilidade de determinar precisamente a localização de sílica depositada.

PARRY et alii (1984), observaram que as gramineas são ricas em silício, no entanto hã uma variação de teo res entre diferentes espécies. O acúmulo ocorre frequentemen te nas camadas de paredes celular de endoderme da raiz, havendo também nas brácteas da inflorescência de gramineas. No entanto foi obtido uma boa resposta da silica no desenvolvimento e produção de cevada podendo ser considerado como importante para a cultura, (ESTEBAN et alii, 1984). MIYAKE \& TAKAHASHI (1983), observaram que em solo aluvial, aplicando 700 a $1400 \mathrm{~kg} \mathrm{SiO} / \mathrm{ha} / \mathrm{ano}$, promovem maior desenvolvimento e produção de pepino, reduzindo a incidência de doença.

\subsection{Interação entre silício e o fósforo}

Um aspecto importante relacionado ao comporta- 
mento do silício, diz respeito ao fósforo no solo e na plan ta.

A literatura internacional apresenta alguns trabalhos de pesquisa nos quais tem sido demonstrado que a presença de silício aumenta o aproveitamento de fósforo aplicado no solo. KHAN \& ROY (1964) constataram que o silício pode exercer algumas funções do $P$ inclusive substitui-lo parcialmente. Foi constatado também por DEWAN \& HUNTER (1949), que a aplicação de silicato de sódio e magnésio aumentou o teor de $\mathrm{P}$ na soja, porém, a absorção de $\mathrm{P}$, aumentou somente em presença de baixas relações de fósforo, concordando com as observações de RALEIGH (1953). Por outro lado, ROTHBUHR \& SCOTT (1957), usando silicio radioativo, mostraram que a adição de fósforo reduz levemente a quantidade de silício, absorvido pelo trigo, tendo o silicato acelerado a absorção de fósforo. Segundo estes autores, existe uma estreita relação do metabolismo do silício e fósforo.

Segundo Roy, citado por GURGEL (1979), a absor ção de fósforo e silicio pelas plantas cultivadas em solução nutritiva é função das espécies, sendo que a presença de silício e fósforo acelerou a absorção de $\mathrm{P}$ em alface e milho, inibindo-a em arroz e cana-de-açúcar. De modo geral, a presença de fósforo inibiu a absorção de silício pelas plantas, sendo essa inibição maior quando o fósforo e o silício foram 
fornecidos às plantas na mesma proporção.

Conforme Gaussamn, citado por JONES \& HANDRECK (1967), o aumento do fornecimento do fósforo produz aumentos sistemáticos na produção de matéria seca, acompanhado pela diminuição de concentração de silica nas piantas.

Em solos havaianos, SHERMANN (1969) obteve res posta à aplicação de Si na forma de silicato de cálcio no ren dimento de capim sudão. Notou-se neste trabalho que a respos ta à aplicação de $\mathrm{P}$ pela cultura foi bem maior com a aplicação de silicato de cálcio do que com carbonato de cálcio; com a metade da aplicação de $\mathrm{P}$ nos vasos contendo silicato de cál cio, o rendimento de capim sudão foi bastante considerável em relação à produção dos vasos contendo carbonato, mesmo com maiores niveis de $P$.

Além do fosfato, o silicato e outros ânions co mo nitrato, bicarbonato,.. molibdato, selenito, etc., são capa zes de coordenar-se com Fe e Al para formar compostos estáveis (HINGSTON et alii, 1968 e 1972). Estes ânions devem então, em princípio, serem capazes de competir com os ânions fosfatos pelos mesmos sitios de adsorção do solo.

Vários autores (RÃJAN, 1975; RÃJAN \& PERROT, 1975; RÃJAN \& WATKINSON, 1976; KAFKAFI, 1968; OBIHARA \& RUSSEL, 1972; REIFENBERG \& BUCKWOLD, 1954) observaram liberação de Si para a solução, com adsorção de $\mathrm{P}$ em argilas, aluminos silicatos e solos. Esta liberação de Si tem sido explicada em termos de deslocamento do Si das estruturas da argila e 
aluminossilicatos pelo P (KAFKAFI, 1968; RÃJAN, 1975).

Segundo PLUCKNETT (1972), a aplicação de silicato aumenta a solubilidade de fósforo no solo, diminui a fixação de fertilizantes fosfatados, corrige as deficiências de cálcio e magnésio e aumenta $\circ \mathrm{pH}$ do solo. Foi verificado por SCARSETH (1965) que quantidades crescentes de silicato de sódio adicionado em solos ácidos, aumentava o P na solução. Da mesma forma, RoY et alii (1971) observaram que a adi ção de doses crescentes de silicato de cālcio ("basic slag" da TVA) a solos havaianos diminui a adsorção de P. Estes efeitos tanto poderiam ser devidos a uma competição de silicą to pelos sitios de adsorção como o aumento do $\mathrm{pH}$, ou ainda devido a ambos os fatores.

Na Austrália, HINGSTON et alii (1968) constatą ram um decréscimo na adsorção de $\mathrm{P}$ pela goetita devido à adi ção de Si, fato que atribuîram à capacidade do Si em aumentar a carga negativa da superficie ao ser adsorvido. Estes dados indicam que a aplicação do Si deve aumentar a disponibilidade do $P$ para as plantas pelo aumento da solubilidade do $P$ adsorvido e decréscimo da capacidade de adsorção de $\mathrm{P}$ pelos solos.

Uma relação linear entre a quantidade de silicato adsorvido e o fosfato liberado foi mostrada por OBIHARA \& RUSSEL (1972). Esta relação foi de 3 a 4 moles de silicato adsorvido por mol de fosfato liberado. Portanto, a correção da acidez do solo com silicato além de aumentar $\circ \mathrm{pH}$, pode- 
ria favorecer a disponibilidade de $P$ para as plantas, devido a este efeito adicional de deslocamento do $P$ adsorvido para a solução pelo silicato. Mas, segundo os dados de OBIHARA \& RUSSEL (1972), esse efeito adicional parece ser significante somente a pH acima de 7. Porém, RAUPACK \& PIPPER (1959), em experimento de laboratório observaram um efeito depressivo do silicato de potássio na adsorçà̉o de $\mathrm{P}$ em um solo laterítico da Austrália, mesmo em pH abaixo de 6. Contudo o efeito maior foi também observado em pH acima de 7 .

Nos solos, os ions silicatados e fosfatos competem pelos mesmos sitios de adsorção (MCKEAGUE \& CLINE, 1963; OBIHARA \& RUSSEL, 1972). Aumentos do teor de P disponí vel no solo pela adição de escórias e outros componentes silicatos são citados por TAYLOR (1961) e SMITH \& SANCHES(1980). Trabalhando com amostras de dois latossolos do Estado de Minas Gerais (LRD \& LEdm), OLIVEIRA (1964) observou um deslocą mento recíproco fósforo-silício, sendo o silício mais facilmente deslocável pelo fósforo do que o contrário, quando pre sentes em altas concentrações. Sob altas concentrações de fós foro, o silício pode ser trocado, inclusive aquele da estrutura da argila (RÃJAN, 1975; RÃJAN \& FOX, 1975; ADAMS et alii, 1982).

A partir desses trabalhos, é de se prever que a aplicação de quantidades crescentes de fósforos em solos oxidicos desloquem cada vez mais silício para a solução de solo. Em se tratando de solos pobres de silicio, esse deslo- 
camento poderia afetar aspectos pedogenéticos, com consequên cias indesejāveis. BROWN \& MAHLER (1987) observaram que o au mento de acidez na presença de fósforo aumentou a concentração de silica em níveis elevados.

LIN \& HUNG (1980) pesquisaram o efeito sinergẹ tico entre si e fósforo na nutrição mineral de arroz e conclui que há uma relação entre $\mathrm{Si}$, e $\mathrm{P}$ semelhante a $\mathrm{Ca}$ e $\mathrm{K}$. Foi constatado também por DONG et alii (1981) que o silicato e o zinco proporcionaram maior crescimento e aumentaram o no de panículas e de grãos de arroz. Verificaram tambēm que - silicato contribuiu para o aumento da disponibilidade de $P$ no solo.

\subsection{Termofosfato magnesiano e seu emprego na agricultura}

O termofosfato magnesiano, conhecido no Pais como YOORIN (YO), da Fertilizantes Mitsui é obtido por via térmica, pelo aquecimento de rocha fosfatada à temperatura aproximada de $1.500^{\circ} \mathrm{C}$, com silicato de magnésio, possibilitando aumentar a solubilidade de fósforo.

Os produtos fosfatados proveniente do tratamen to térmico caracterizam-se por serem praticamente insolúveis em água, solúveis em ácido cítrico e em citrato de amônio mais āgua.

Estudando a eficiência agronômica de 11 fontes de fósforo, mais especificamente em solos sob vegetação de 
cerrado, durante oito anos, GOEDERT \& LOBATO (1984) concluiram que o termosfosfato magnesiano e hiperfosfato de gafsa foram similares ao Superfosfato Triplo como supridores de fós foro para as plantas, desde o primeiro cultivo, quando foram aplicados a lanço e incorporados ao solo. 


\section{MATERIAL E MÉTODOS}

\subsection{Localização dos ensaios}

o ensaio foi instalado e conduzido em casa de vegetação no Departamento de Ciências do Solo da Faculdade de Ciências Agronômicas "Campus" de Botucatu-UnESP, Estado de são Paulo.

\subsection{Solo utilizado}

Foi utilizada amostra superficial $(0-20 \mathrm{~cm})$ de um sólo, classificado por CARVALHo et alii (1983), como pertencendo ao Grande Grupo Latossolo Vermelho Escuro-álico(LEa), classe textural franco argilo-arenoso, Unidade Patrulha, coletado da Fazenda Experimental Lageado da Faculdade de Ciências Agronômicas de Botucatu-UNESP.

A terra coletada, foi secada ao ar e peneirada a uma malha granulométrica de $4 \mathrm{~mm}$. Uma parte da terra foi destinada para sua caracterização. As análises físicas e quí micas foram feitas com terra fina seca ao ar. 
Na análise granulométrica segụiu-se o método de KILMER \& ALEXANDER (1949). A dispersão foi feita com hexą metafosfato de sódio e agitação lenta por 10 minutos seguida de agitação em alta rotação,(12000 rpm) por 5 minutos. A fra ção areia foi separada utilizando-se de peneira e a fração argila por meio de pipeta. o silte foi determinado por diferença. Os resultados encontram-se na Tabela 1.

As análises quimicas iniciais foram executadas sendo: a) valor $\mathrm{pH}$ determinado em potenciômetro "MICRONAL B 374 ", com eletrodo de vidro, empregando-se a relação solo: solu ção $1: 2,5$ (pH em água); b) matēria orgānica, pelo mētodo Wal kley \& Black e cālcio, magnēsio e potássio trocāveis extraídos por acetato de amônio $\mathrm{N} \mathrm{pH} \mathrm{7,0} \mathrm{(JACKSON,} \mathrm{1964);} \mathrm{C)} \mathrm{fósfó}$ ro solúvel em $\mathrm{H}_{2} \mathrm{SO}_{4} 0,05 \mathrm{Ne}$ hidrogênio + aluminio extraídos por acetato de cálcio $\mathrm{N}$ pH 7,0 (CATANI, et alii, 1955). Foram determinados tambēm os teores de $\mathrm{SiO}_{2}, \mathrm{Al}_{2} \mathrm{O}_{3} \mathrm{e}$ $\mathrm{Fe}_{2} \mathrm{O}_{3}$ da fração argila Go et alii, 1986). Os resultados encontram-se na Tabela 1.

\subsection{Tratamentos}

As" fontes de fósforos utilizadas e quantidades aplicadas, bem como as composições percentuais, são as seguintes: 
FONTE

YOORIN (YO)

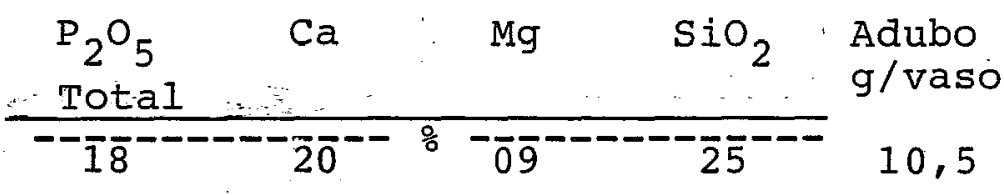

YOOSIRIN (YS)

10

24

04

30

18,9

SUPERFOSFATO TRIPLO (ST) 42

18

4,5

YOOSIRIN (YS) è um produto termosfosfato com adição de silicato de cálcio (subproduto das usinas siderūrgicas) com alto teor de $\mathrm{SiO}_{2}$ e de Ca.

As diferentes fontes foram repetidas por sete vezes, resultando nas seguintes épocas e dias de incubação.

$$
\begin{aligned}
& 1 \text { a época - } 90 \text { dias - aplicação em } 07 / 04 / 88 \\
& 2 \underline{a} \text { época - } 75 \text { dias - aplicação em } 22 / 04 / 88 \\
& 3 a \text { ápoca - } 60 \text { dias - aplicação em } 07 / 05 / 88 \\
& 4 a \text { época - } 45 \text { dias - aplicação em } 22 / 05 / 88 \\
& 5 \underline{a} \text { época - } 30 \text { dias - aplicação em 06/06/88 } \\
& 6 \underline{a} \text { época - } 15 \text { dias - aplicação em } 21 / 06 / 88 \\
& \text { 7ạ época - } 0 \text { dias - aplicação em } 0.6 / 07 / 88
\end{aligned}
$$

Tabela 1. Caracteristica física e química do solo utilizado.

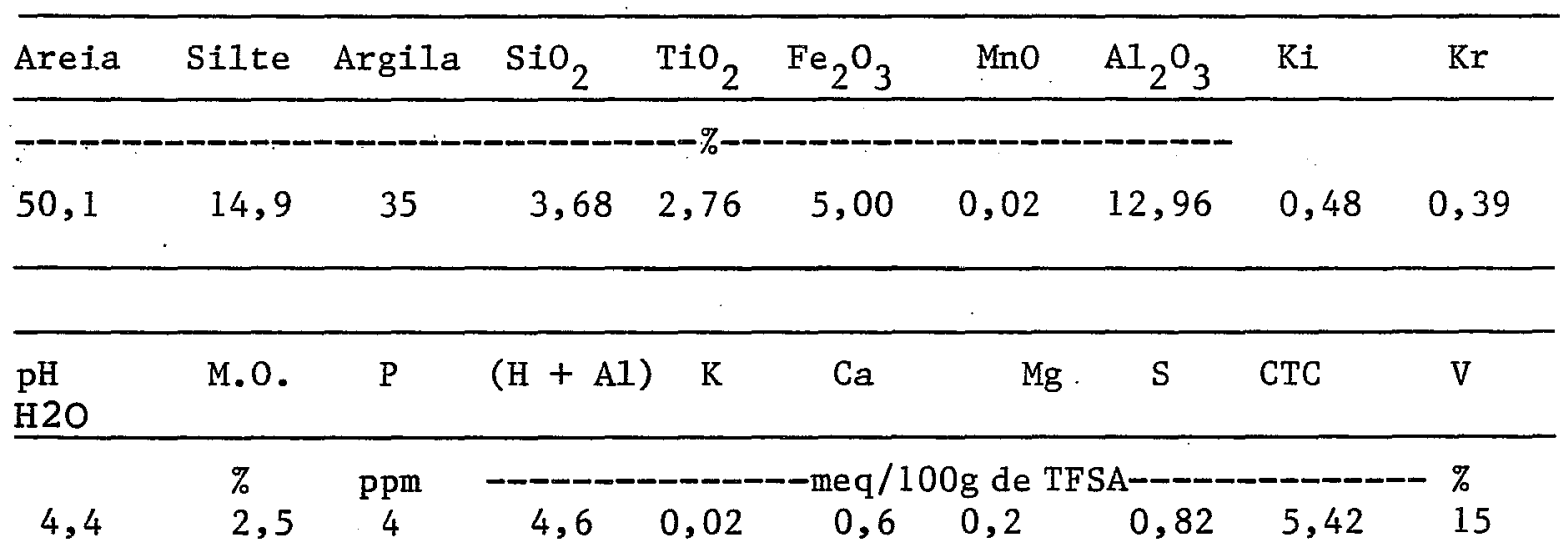


Após a coleta de amostras de solo para análi-. se química $(06 / 07 / 88)$ foram transplantadas, em cada vaso, mu das de alface (Lactuca sativa L.) da variedade Brasil 201, com a finalidade de se verificar o desenvolvimento vegetativo em função do teor de fósforo disponivel.

Durante todo o periodo do ensaio vegetativo, a cada quinze dias, foi fornecido solução nutritiva isenta de fósforo, cálcio e magnésio, seguindo bases preconizadas por WAUGH \& FITTS (1966). A irrigação foi feita com água desmine ralizada.

A colheita foi feita aos 46 dias após o transplan te determinando-se o peso de matēria seca produzida em cada vaso. Em seguida as plantasforam lavadas com solução de detergente "Extran" 0,1\% seguida de lavagem com água desminerali zada, secas em estufa a $60^{\circ} \mathrm{C}$ até atịngir peso constante e, em continuidade, eram pesadas para obtenção do peso de matéria seca moídas em moinho tipo wiley para posterior análise química dos teores de fósforo, potássio, cálcio e magnésio.

\subsection{Ensaio em casa vegetação}

Após a colocação de 5,0 litros de terra passada em peneira a malha de $4 \mathrm{~mm}$ em cada vaso, foram aplicadas, a cada quinze dias, quantidades equivalentes de $150 \mathrm{ppm}$ de $P$ das diferentes fontes, umedecidas à aproximadamente $70 \%$ do. poder de embebição, mantendo-se incubação em ambiente escuro. 


\subsection{Delineamento experimental}

o experimento constou da aplicação de 3 fontes de fósforo em 7 épocas diferentes, com 4 repetições, totalizando 84 parcelas distribuidas num delineamento inteiramente casualizado e, esquema fatorial (GoMES, 1984):

\begin{tabular}{lc}
\hline $\begin{array}{l}\text { Causas de } \\
\text { Variação }\end{array}$ & $\begin{array}{c}\text { Graus de } \\
\text { Liberdade }\end{array}$ \\
\hline Fontes (F) & 2 \\
Epocas (E) & 6 \\
Interação F $\mathrm{E}$ & 12 \\
(Tratamentos) & $120)$ \\
Residuo & 63 \\
\hline TotAL & 83
\end{tabular}

3.6. Análise química do solo após a incubação

Após completado o período de incubação correspondente a cada tratamento, foram retiradas amostras de solo de cada vaso para análise química, conforme métodos descritos em 3.2. Foram também determinados os teores de. fósforo extraido por resina trocadora (RAIJ \& QUAGGIO, 1983). 


\subsection{Análise química do material vegetal}

As análises químicas do material vegetal foram feitas seguindo técnica descrita por MALAVOLTA (1964).

o material vegetal foi digerido com adição de ácido nítrico e ácido perclórico, sendo a solução mineral re colhida em balão de $50 \mathrm{ml}$ donde se tomaram alíquotas para a determinação de fósforo por fotocolorimetria e de potássio, cálcio e magnésio em espectrofotômetro de absorção atômica de (Perkin-Elmer, modelo 305-B.).

\subsection{Anālise estatistica}

As análises estatisticas foram executadas no Polo Computacional do Lageado da Faculdade de Ciências Agronômicas de Botucatu-UNESP, utilizando-se de programas já estabelecidos. Todos os dados obtidos foram submetidos à análi se de variāncia e Teste de Tukey. 


\section{RESULTADOS E DISCUSSÃO}

4.1. Fósforo solúvel, bases trocáveis e acidez do solo

Os efeitos da aplicação das 3 diferentes fontes de fosfato em diferentes épocas nas propriedades quimicas foram avaliados em amostras coletadas no dia do transplante da alface e os resultados estão apresentados a seguir.

4.1.1. $\mathrm{P}$ solúvel em $\mathrm{H}_{2} \mathrm{SO}_{4} 0,05 \mathrm{~N}$ e extraído: por resi na trocadora.

Os teores de fósforo solüvel em $\mathrm{H}_{2} \mathrm{SO}_{4} 0,05 \mathrm{~N}$ en contram-se na Tabela 2 e são apresentados graficamente na Fi gura 1. Verifica-se que houve diferença significativa entre as fontes, com exceção da época 4 ( 45 dias de incubação), sen do que yo e ST apresentaram médias estatisticamente iguais e ambas diferentes da fonte YS, que apresentou teores de fósforo disponivel maiores que as outras fontes, demonstrando uma maior eficiência na diminuição $\cdots$ da insolubilidade de fósforo pelos componentes do solo. Ainda com relação à Tabela 2 verifica-se que a época de incubação 
influi apenas na fonte YS, com acentuada diferença entre as épocas 3 (60 dias) e 4 (45 dias). Essa acentuada reação na disponibilidade de fósforo numa determinada época de incubação, que pode ser melhor visualizada na Figura 1, também foi observada por NAKAGAWA et alii (1983) em trabalhos semelhantes utilizando-se termofosfato Yoorin (fonte Yo), que no pre sente experimento não apresentou a mesma tendência. Isto, se gundo aqueles autores, pode levar a supor que após uma fase de solubilização, o fósforo solúvel reagiria com componentes minerais, principalmente de ferro e aluminio deslocando equilíbrio entre os fosfatos solúveis e não solúveis, e após um periodo mais longo de incubação ocorreria um estabelecimento de equilibrio entre aquelas duas formas de fosfato. Um fato bastante interessante foi observado quando o fósforo foi extraido por resina trocadora onde o ys mostrou-se bastante solúvel no inicio do periodo de incubação (Tabela 3). Esses dados estão representados graficamente na Figura 3. Deste fa to, presume-se que no inicio houve uma influência de outros ions que possater elevado o valorobtido. Com o passar do tem po, o produto provavelmente reagiu com as partículas do solo normalizando as reações. : Observou-se que aos 60 dias tambēm houve uma acentuada diferença, coincidindo com a extração feita pelo $\mathrm{H}_{2} \mathrm{SO}_{4}, 05 \mathrm{~N}$ quando a fonte utilizada foi - YS. Porēm quando comparamos as duas formas de extrações de fósforo utilizando-se a fonte YS, observou-se que. o $\mathrm{H}_{2}$ $\mathrm{So}_{4} 0,05 \mathrm{~N}$ apresentou um comportamento que mais se assemelhou às curvas do fósforo absorvido pela planta e produção de matéria seca. 
Tabela 2. Teores de fósforo solüvel em $\mathrm{H}_{2} \mathrm{SO}_{4} 0,05 \mathrm{~N}$, obtidos em amostras de terra após diferentes tempos de incubação para 3 fontes de fósforo.

$$
\text { P solúvel em } \mathrm{H}_{2} \mathrm{SO}_{4}, 0,05 \mathrm{~N}
$$

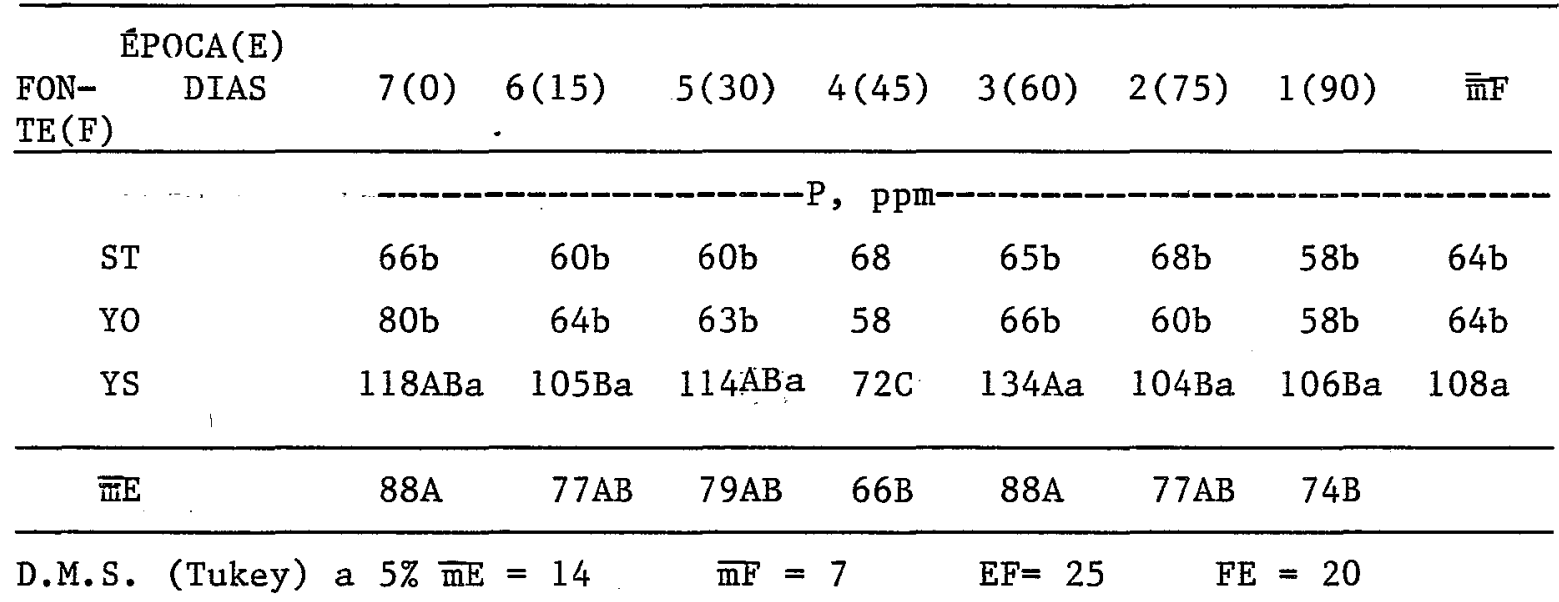

1. Médias com letras maiúsculas diferentes na mesma linha di ferem estatisticamente entre si.

2. Médias com letras minúsculas diferentes na mesma coluna di ferem estatisticamente entre si.

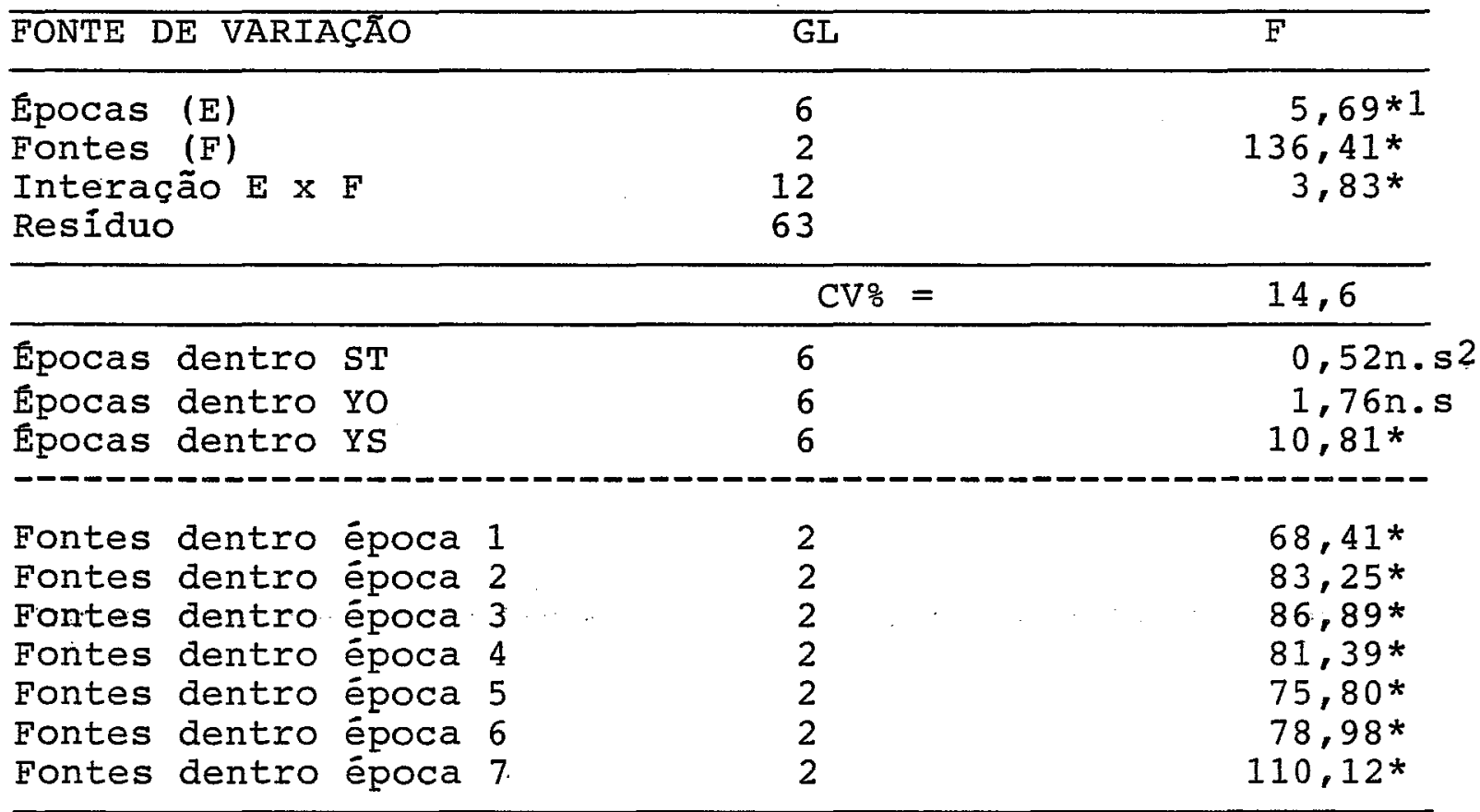

1. Significativo ao nível de 5\%

2. não significativo 
Tabela 3. Teores de fósforo extraỉdo por resina trocadora, obtidos em amostras de terra após diferentes tempos de incubação para 3 fontes de fósforo.

P extraído por resina trocadora

\begin{tabular}{|c|c|c|c|c|c|c|c|c|c|}
\hline \multirow[b]{2}{*}{$\begin{array}{l}\text { FON- } \\
\text { TE }(F)\end{array}$} & \multicolumn{2}{|l|}{ EPOCA (E) } & \multirow[b]{2}{*}{$6(15)$} & \multirow[b]{2}{*}{$5(30)$} & \multirow[b]{2}{*}{$4(45)$} & \multirow[b]{2}{*}{$3(60)$} & \multirow[b]{2}{*}{$2(75)$} & \multirow[b]{2}{*}{$1(90)$} & \multirow[b]{2}{*}{$\overline{\mathrm{m}} \mathrm{F}$} \\
\hline & DIAS & $7(0)$ & & & & & & & \\
\hline & & & & $---F$ & , ppm- & & & & \\
\hline ST & & $170 \mathrm{Ab}$ & $86 B$ & $94 \mathrm{Bab}$ & $118 \mathrm{Ba}$ & $104 \mathrm{Bb}$ & $114 \mathrm{Ba}$ & $97 \mathrm{Bab}$ & $112 b$ \\
\hline YO & & $170 \mathrm{Ab}$ & $108 \mathrm{~B}$ & $71 \mathrm{Bb}$ & $69 \mathrm{Bb}$ & $87 \mathrm{Bb}$ & $72 \mathrm{Bb}$ & $80 \mathrm{Bb}$ & $94 c$ \\
\hline YS & & $232 \mathrm{Aa}$ & $106 \mathrm{BC}$ & $114 \mathrm{BCa}$ & $98 \mathrm{Cab}$ & $146 \mathrm{Ba}$ & $132 \mathrm{Bca}$ & $127 \mathrm{Bca}$ & $136 a$ \\
\hline$\overline{\mathrm{m}} \mathrm{E}$ & & $191 \mathrm{~A}$ & $100 \mathrm{~B}$ & $93 B$ & $95 B$ & $112 \mathrm{~B}$ & $106 \mathrm{~B}$ & $101 B$ & \\
\hline
\end{tabular}

D.M.S. (Tukey) a 5\% $\overline{\mathrm{m}} \mathrm{E}=26 \quad \overline{\mathrm{m} F}=13 \quad \mathrm{EF}=45 \quad \mathrm{FE}=36$

1. Médias com letras maiúsculas diferentes da mesma linha di ferem estatisticamente entre si.

2. Médias com letras minúsculas diferentes na mesma coluna di ferem estatisticamente entre si.

\begin{tabular}{|c|c|c|}
\hline FONTE DE VARIAÇÃO & GL & $\mathbf{F}$ \\
\hline $\begin{array}{l}\text { Epocas }(E) \\
\text { Fontes (F) } \\
\text { Interação E x F } \\
\text { Residuo }\end{array}$ & $\begin{array}{r}6 \\
2 \\
12 \\
63\end{array}$ & $\begin{array}{l}32,38 * 1 \\
29,14 * \\
2,64 *\end{array}$ \\
\hline & $\mathrm{CV} \%=$ & 18,4 \\
\hline $\begin{array}{l}\text { Epocas dentro ST } \\
\text { Epocas dentro YO } \\
\text { Epocas dentro YS }\end{array}$ & $\begin{array}{l}6 \\
6 \\
6\end{array}$ & $\begin{array}{r}7,13 * \\
11,93 * \\
18,59 *\end{array}$ \\
\hline $\begin{array}{lll}\text { Fontes dentro época } & 1 \\
\text { Fontes dentro época } & 2 \\
\text { Fontes dentro época } & 3 \\
\text { Fontes dentro época } & 4 \\
\text { Fontes dentro época } & 5 \\
\text { Fontes dentro época } & 6 \\
\text { Fontes dentro época } & 7\end{array}$ & $\begin{array}{l}2 \\
2 \\
2 \\
2 \\
2 \\
2 \\
2\end{array}$ & $\begin{array}{r}48,92 * \\
60,60 * \\
56,74 * \\
64,07 * \\
43,77 * \\
59,39 * \\
175,63 *\end{array}$ \\
\hline
\end{tabular}

1. Significado ao nivel de $5 \%$. 


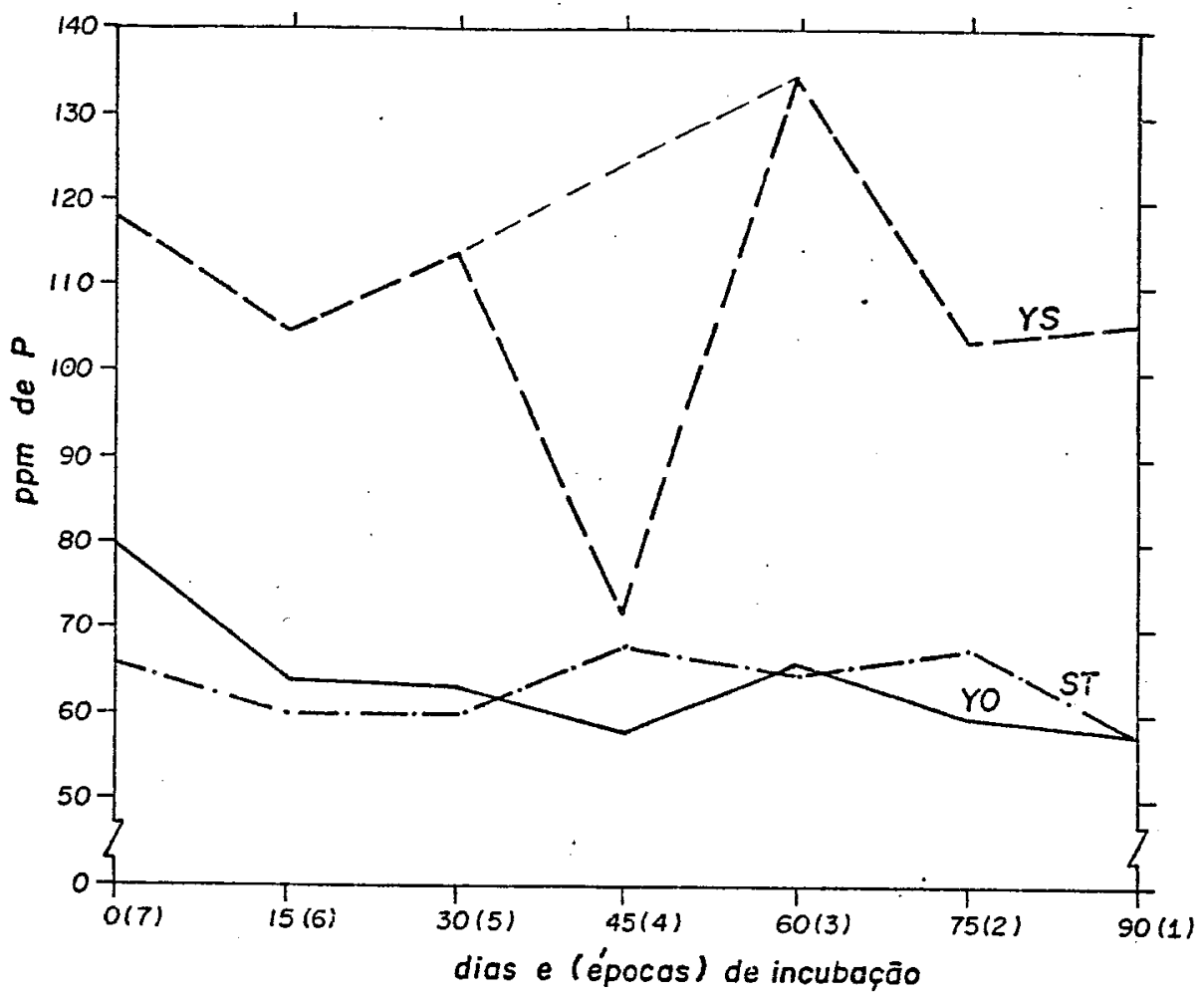

Figura. 1. Teores de fósforo solúvel em $\mathrm{H}_{2} \mathrm{SO}_{4} 0,05 \mathrm{~N}$

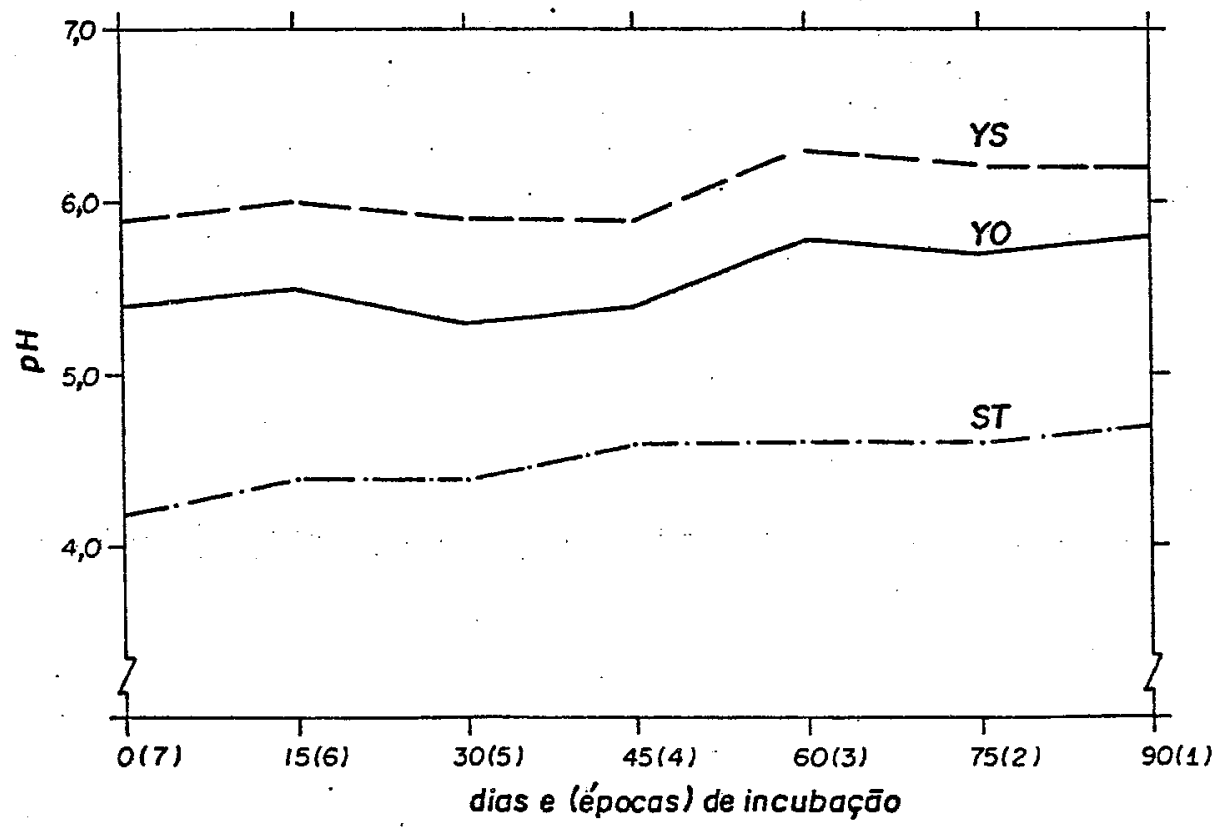

Figura 2. Valores de $\mathrm{pH}$ do solo 


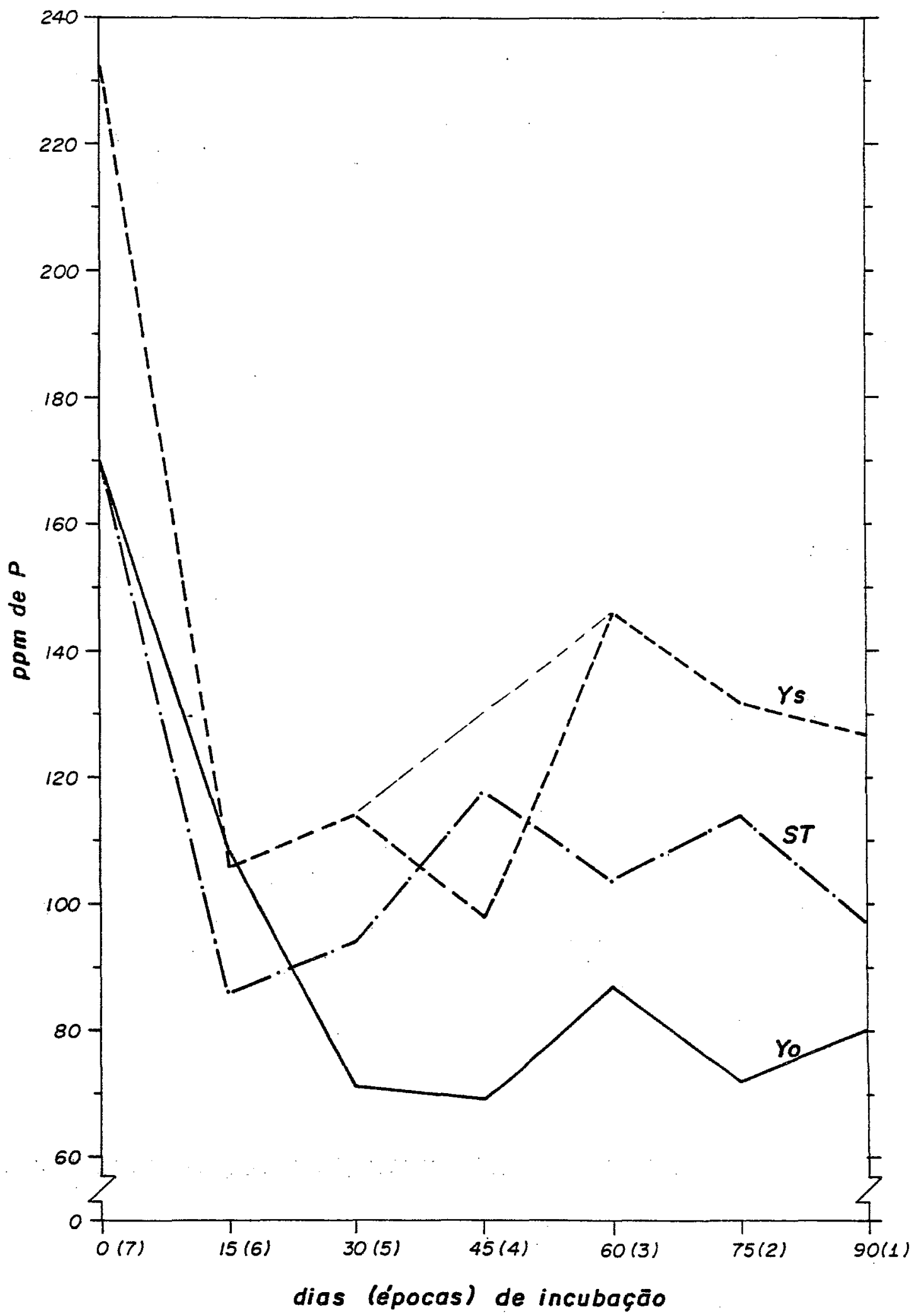

Figura 3. Teores de fösforo extraỉdo por resina trocadora 


\subsection{2. $\mathrm{Ca}^{2}+\mathrm{e} \mathrm{Mg^{2 } +}$ trocáveis}

... Os valores médios de câlcio e magnésio trocáveis estão representados respectivamente nas Tabelas 4 e 5 . O. resultado obtido para valores médios de Ca trocável é de 0,84 para ST, 1,59 para O Yo e 2,38 para YS (valores em meq/ $100 \mathrm{~g}$ TFSA). Este resultado é coerente quando se observa a composicão das fontes, onde o YS possui maior teor de Ca que - Yo e este por sua vez possui maior teor que o ST.

o comportamento dos valores médios para o magnésio se assemelham aos obtidos para o cálcio, porēm estes valores não seguiram a mesma tendēncia em relação aos teores do elemento nas fontes, pois o yo, neste caso, contém maior teor de magnēsio em sua composição que o ys. Uma provável ex plicação para este fato pode ser aomaior teor de silício no YS do que no Yo, que aumentaria a disponibilidade do magnésio.

Com relação às três fontes de fósforo, observa -se que na Figura 4 também houve uma acentuada diferença nos teores de $\mathrm{Ca}+\mathrm{Mg}$ aos 60 dias.

\subsubsection{Acidez do solo}

$\mathrm{O} \mathrm{pH}$ elevou-se desde os primeiros dias de incu bação, quando da aplicação do YS ao solo, acentuando-se mais aos 60 dias (tabela 6). Este fato è muito importante na 
Tabela 4. Teores de cálcio trocāvel, obtidos em amostras de terra após diferentes tempos de incubação para e fontes de fósforo.

Ca.: Trocável

\begin{tabular}{|c|c|c|c|c|c|c|c|c|}
\hline FONTE (F) $\begin{array}{c}\text { FPOCA (E) } \\
\text { DIAS }\end{array}$ & $7(0)$ & $6(15)$ & $5(30)$ & $4(45)$ & $3(60)$ & $2(75)$ & $I(90)$ & $\overline{\bar{m}} \mathrm{~F}$ \\
\hline ST & $0,88 c$ & $0,90 c$ & $0,85 c$ & 0,80 & $0,78 c$ & $0,85 c$ & $0,85 c$ & $0,84 c$ \\
\hline YO & $1,10 \mathrm{Db}$ & $1,72 \mathrm{ABb}$ & $1,48 \mathrm{Cb}$ & $1,62 \mathrm{BCb}$ & $1,85 \mathrm{Ab}$ & $1,60 \mathrm{BCb}$ & $1,75 \mathrm{ABb}$ & $1,59 \mathrm{~b}$ \\
\hline YS & $1,55 \mathrm{Da}$ & $2,40 \mathrm{BCa}$ & $2,35 \mathrm{Ca}$ & $2,30 \mathrm{Ca}$ & $2,90 \mathrm{Aa}$ & $2,58 \mathrm{Ba}$ & $2,60 \mathrm{Ba}$ & $2,38 a$ \\
\hline$\overline{\overline{\mathrm{m}}} \mathrm{E}$ & $1,18 \mathrm{E}$ & $1,68 \mathrm{BC}$ & $1,56 \mathrm{D}$ & $1,58 \mathrm{CD}$ & $1,84 \mathrm{~A}$ & $1,68 B C$ & $1,73 \mathrm{AB}$ & \\
\hline
\end{tabular}

D.M.S. (Tukey) a $5 \% \overline{\mathrm{m}} \mathrm{E}=0,12 \quad \overline{\mathrm{m} F}=0,06 \quad \mathrm{EF}=0,21 \quad \mathrm{FE}=0,16$

1. Médias com letra maiúsculas diferenres na mesma linha diferem estatisticamente entre si.

2. Médias com letra minúsculas diferentes na mesma coluna di ferem estatisticamente entre si.

\begin{tabular}{|c|c|c|}
\hline FONTE DE VARIAÇÃO & GL & $F$ \\
\hline $\begin{array}{l}\text { Epocas (E) } \\
\text { Fontes (F) } \\
\text { Interação E x F } \\
\text { Residuo }\end{array}$ & $\begin{array}{r}6 \\
2 \\
12 \\
63\end{array}$ & $\begin{array}{r}57,23 *^{1} \\
1.756,68 * \\
21,87 *\end{array}$ \\
\hline & $\mathrm{CV}$ 응 $=$ & 6,0 \\
\hline $\begin{array}{l}\text { Epocas dentro ST } \\
\text { Epocas dentro YO } \\
\text { Epocas dentro YS }\end{array}$ & $\begin{array}{l}6 \\
6 \\
6\end{array}$ & $\begin{array}{l}0,77 \mathrm{~ns}^{2} \\
25,84^{*} \\
74,36^{*}\end{array}$ \\
\hline $\begin{array}{lll}\text { Fontes dentro época } & 1 \\
\text { Fontes dentro época } & 2 \\
\text { Fontes dentro época } & 3 \\
\text { Fontes dentro época } & 4 \\
\text { Fontes dentro época } & 5 \\
\text { Fontes dentro época } & 7\end{array}$ & $\begin{array}{l}2 \\
2 \\
2 \\
2 \\
2 \\
2\end{array}$ & $\begin{array}{r}324,35^{*} \\
316,85^{*} \\
478,15^{*} \\
239,03^{*} \\
240,44^{*} \\
50,03^{*}\end{array}$ \\
\hline
\end{tabular}

1. significativo ao nivel de $5 \%$

2. não significativo. 
Tabela 5. Teores de magnésio trocável, obtidos em amostras de terra após diferentes tempos de incubação para 3 fontes de fósforo.

Mg trocável

\begin{tabular}{|c|c|c|c|c|c|c|c|c|c|}
\hline $\begin{array}{l}\text { FONTE } \\
\text { (F) }\end{array}$ & $\begin{array}{l}\text { EPOCA(E) } \\
\text { DIAS }\end{array}$ & $7(0)$ & $6(15)$ & $5(30)$ & $4(45)$ & $3(60)$ & $2(75)$ & $1(90)$ & $\overline{\mathrm{m}} \mathrm{F}$ \\
\hline & & $----n-n$ & - & ------ & meq/100m 1 & TFSA- - & $---\infty-n---$ & ט--n-a-n & $--m--n$ \\
\hline ST & 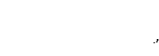 & $0,15 \mathrm{c}$ & $0,12 c$ & $0,10 c$ & $0,15 \mathrm{c}$ & $0,10 c$ & $0,12 \mathrm{c}$ & $0,10 \mathrm{c}$ & $0,12 c$ \\
\hline YO & & $0,68 \mathrm{Db}$ & $1,22 \mathrm{Bb}$ & $1,02 \mathrm{Cb}$ & $1,15 \mathrm{BCb}$ & $1,50 \mathrm{Ab}$ & $1,22 \mathrm{Bb}$ & $I, 28 \mathrm{Bb}$ & $1,15 b$ \\
\hline YS & & $0,92 \mathrm{Da}$ & $1,72 \mathrm{Ca}$ & $1,70 \mathrm{Ca}$ & $1,75 \mathrm{Ca}$ & $2,30 \mathrm{Aa}$ & $1,98 \mathrm{Ba}$ & $2,02 \mathrm{Ba}$ & $1,77 \mathrm{a}$ \\
\hline$\overline{\mathrm{mE}}$ & & $0,58 \mathrm{E}$ & $1.02 \mathrm{CD}$ & $0,94 \mathrm{D}$ & $1,02 \mathrm{CD}$ & $1,30 \mathrm{~A}$ & $1,11 \mathrm{BC}$ & $1,13 \mathrm{~B}$ & \\
\hline
\end{tabular}

D.M.S. (Tukey) a 5\% $\overline{\mathrm{m} E}=0,10 \quad \overline{\mathrm{m} F}=0,05 \quad \mathrm{EF}=0,17 \quad \mathrm{FE}=0,14$

1. Médias com letras maiúsculas diferentes na mesma linha dí ferem estatisticamente entre si.

2. Médias com letras minúsculas diferentes na mesma coluna di ferem estatisticamente entre si.

\begin{tabular}{|c|c|c|}
\hline FONTE DE VARIAÇÃO & GL & $\mathbf{F}$ \\
\hline $\begin{array}{l}\text { Epocas (E) } \\
\text { Fontes (') } \\
\text { Interação } \mathrm{E} \text { X } \mathrm{F} \\
\text { Residuo }\end{array}$ & $\begin{array}{r}6 \\
2 \\
12 \\
63\end{array}$ & $\begin{array}{r}92,58 *^{1} \\
3.045,59 * \\
32,11 *\end{array}$ \\
\hline & $C V=$ & 7,9 \\
\hline $\begin{array}{l}\text { Epocas dentro ST } \\
\text { Epocas dentro YO } \\
\text { Epocas dentro YS }\end{array}$ & $\begin{array}{l}6 \\
6 \\
6\end{array}$ & $\begin{array}{c}0,32 \mathrm{n} . \mathrm{s}^{2} \\
40,75^{*} \\
115,75^{*}\end{array}$ \\
\hline $\begin{array}{lll}\text { Fontes dentro época } & 1 \\
\text { Fontes dentro época } & 2 \\
\text { Fontes dentro época } & 3 \\
\text { Fontes dentro época } & 4 \\
\text { Fontes dentro época } & 5 \\
\text { Fontes dentro época } & 6 \\
\text { Fontes dentro época } & 7\end{array}$ & $\begin{array}{l}2 \\
2 \\
2 \\
2 \\
2 \\
2 \\
2\end{array}$ & $\begin{array}{l}589,33^{*} \\
542,00 * \\
776,21 * \\
409,23^{*} \\
403,76 * \\
419,40 * \\
97,81 *\end{array}$ \\
\hline
\end{tabular}

1. Significativo ao nível de $5 \%$.

2. Não significativo. 
Tabela 6. Valores de pH obtidos em amostras de terra após di diferentes tempos de incubação para 3 fontes de fós foro.

\begin{tabular}{|c|c|c|c|c|c|c|c|c|c|}
\hline \multirow[b]{2}{*}{$\begin{array}{l}\text { FONTES } \\
(F) \\
\end{array}$} & \multirow[b]{2}{*}{$\begin{array}{l}\text { EPOCA(E) } \\
\text { DIAS }\end{array}$} & \multicolumn{8}{|c|}{ Valores de $\mathrm{pH}\left(\mathrm{H}_{2} \mathrm{O}\right)$} \\
\hline & & $7(0)$ & $6(15)$ & $5(30)$ & $4(45)$ & $3(60)$ & $2(75)$ & $1(90)$ & $\overline{\mathrm{m} F}$ \\
\hline ST & & $4,20 D c$ & $4,38 \mathrm{CDC}$ & $4,38 \mathrm{CDc}$ & $4,60 \mathrm{ABC}$ & $4,47 \mathrm{BCc}$ & $4,62 \mathrm{ABC}$ & $4,72 \mathrm{Ac}$ & $4,48 c$ \\
\hline YO & & $5,35 \mathrm{BCb}$ & $5,50 \mathrm{Bb}$ & $5,30 \mathrm{Cb}$ & $5,42 \mathrm{BCb}$ & $5,75 \mathrm{Ab}$ & $5,72 \mathrm{Ab}$ & $5,77 \mathrm{Ab}$ & $5,55 b$ \\
\hline YS & & $5,90 \mathrm{Ca}$ & $6,05 \mathrm{BCa}$ & $5,90 \mathrm{Ca}$ & $5,87 \mathrm{Ca}$ & $6,32 \mathrm{Aa}$ & $6,20 \mathrm{ABa}$ & $6,15 \mathrm{ABa}$ & $6,06 a$ \\
\hline$\overline{\mathrm{mE}}$ & & $5,15 \mathrm{D}$ & $5,31 B$ & $5,19 \mathrm{CD}$ & $5,30 \mathrm{BC}$ & $5,52 \mathrm{~A}$ & $5,52 \mathrm{~A}$ & $5,55 \mathrm{~A}$ & \\
\hline
\end{tabular}

D.M.S. (Tukey) a 5\% $\overline{\mathrm{m}} \mathrm{E}=0,12 \quad \overline{\mathrm{m} F}=0,06 \quad \mathrm{EF} 0,20 \quad \mathrm{FE}=0,16$

1. Médias com letras maiúsculas diferentes na mesma linha di ferem estatisticamente entre si.

2. Médias com letras minúsculas diferentes na mesma coluna di ferem estatisticamente entre si.

\begin{tabular}{|c|c|c|}
\hline FONTE DE VARIAÇÃO & GL & $F$ \\
\hline $\begin{array}{l}\text { Epocas (E) } \\
\text { Fontes (F) } \\
\text { Interação E X F } \\
\text { Residuo }\end{array}$ & $\begin{array}{r}6 \\
2 \\
12 \\
63\end{array}$ & $\begin{array}{r}35,91 *^{1} \\
1.980,87 * \\
4,73 *\end{array}$ \\
\hline & $\mathrm{CV}$ 응 & 1,8 \\
\hline $\begin{array}{l}\text { Epocas dentro ST } \\
\text { Epocas dentro YO } \\
\text { Epocas dentro YS }\end{array}$ & $\begin{array}{l}6 \\
6 \\
6\end{array}$ & $\begin{array}{l}14,31 * \\
17,66 * \\
13,40 *\end{array}$ \\
\hline $\begin{array}{lll}\text { Fontes dentro época } & 1 \\
\text { Fontes dentro época } & 2 \\
\text { Fontes dentro época } & 3 \\
\text { Fontes dentro época } & 4 \\
\text { Fontes dentro época } & 5 \\
\text { Fontes dentro época } & 6 \\
\text { Fontes dentro época } & 7\end{array}$ & $\begin{array}{l}2 \\
2 \\
2 \\
2 \\
2 \\
2 \\
2\end{array}$ & $\begin{array}{l}238,00 * \\
284,72^{*} \\
391,05^{*} \\
182,38^{*} \\
257,45^{*} \\
317,89^{*} \\
328,25^{*}\end{array}$ \\
\hline
\end{tabular}

1. Significativo ao nivel de $5 \%$ 
utilização do mesmo na região dos cerrados, cujos solos normalmente apresentam acidez alta e teores baixos de fósforo., sendo necessāria a prática da calagem e fosfatagem. Normalmente atē a época da semeadura, o indice pluviométrico nessas localidades é baixo dificultando a solubilidade dos corretivos de acidez. Nessas condições do ensaio o ys atingiu praticamente $\circ \mathrm{pH}$ 6,0, apresentando um poder corretivo da acidez do solo, caracterizando uma redução na quantidade de calcário a ser aplicado e conseqủentemente uma diminuição no custo de produção.

o pequeno aumento no pH pela aplicação de ST contraria os dados obtidos por BRAGA \& AMARAL (1971) que observaram um abaixamento do pH pela acidificação causada pela decomposição dupla, dando origem à formação do ácido fosfóri co:

$$
\mathrm{Ca}\left(\mathrm{H}_{2} \mathrm{PO}_{4}\right)_{2} \rightarrow \mathrm{H}_{3} \mathrm{PO}_{4}+\mathrm{CaHPO}_{4} \downarrow
$$

Esta alteração leva a presumir que houve uma diluição do ađū bo no solo (quantidade pequena de adubo em relação à terra). Alie-se ainda, que além de não proporcionar a elevação do pH (Figura 2), a fonte ST, pela própria caracteristica e composição, não foi eficiente em aumentar os niveis de Ca e Mg (Figura 4 e Tabelas 4 e 5 ). Decorrente disto, não houve modi ficação na saturação de bases do solo (Figura 5), ao contrārio ao que ocorreu com as outras duas fontes sendo que houve um incremento quando utilizou Yo e YS demonstrando uma boa avaliação na fertilidade do solo (Tabela 7). 
Tabela 7. Porcentagem de saturação de bases obtidos em amostras de terra após diferentes tempos de incubação para 3 fontes de fósforo.

\begin{tabular}{|c|c|c|c|c|c|c|c|c|c|}
\hline & & \multicolumn{5}{|c|}{ Porcentagem de } & \multicolumn{3}{|c|}{ em bases ( $\mathrm{v} \%$ ) } \\
\hline \multirow[t]{2}{*}{$\begin{array}{l}\text { FONTE } \\
(F)\end{array}$} & $\begin{array}{c}\text { EPOCA (E) } \\
\text { DIAS }\end{array}$ & $7(0)$ & $6(15)$ & $5(30)$ & $4(45)$ & $3(60)$ & $2(75)$ & $1(90)$ & imF \\
\hline & & $---\infty--$ & $\cdots-\infty-\infty$ & $-\infty-\infty-\infty$ & - \%=-- & $--\infty-\infty--\infty$ & 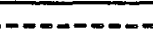 & $-\infty-\infty-\infty$ & $-\infty--n$ \\
\hline ST & & $15,0 c$ & $15,0 \mathrm{c}$ & $13,2 \mathrm{c}$ & $15,0 \mathrm{c}$ & $14,2 \mathrm{c}$ & $15,8 c$ & $16,0 c$ & $14,9 c$ \\
\hline Yo & & $24,0 \mathrm{Db}$ & $40,5 \mathrm{Bb}$ & $35,2 \mathrm{Cb}$ & $40,2 \mathrm{Bb}$ & $45,8 \mathrm{Ab}$ & $43,5 \mathrm{ABb}$ & $47,2 \mathrm{Ab}$ & $39,5 b$ \\
\hline YS & & $31,8 \mathrm{Da}$ & $55,2 \mathrm{Ca}$ & $53,0 \mathrm{Ca}$ & $55,0 \mathrm{Ca}$ & $68,8 \mathrm{Aa}$ & $62,8 \mathrm{Ba}$ & $63,2 \mathrm{Ba}$ & $55,7 a$ \\
\hline$\overline{\overline{\mathrm{m}}} E$ & & $23,6 \mathrm{E}$ & $36,9 \mathrm{C}$ & $33,8 D$ & $36,8 \mathrm{C}$ & $42,9 \mathrm{~A}$ & $40,7 B$ & $42,2 \mathrm{AB}$ & \\
\hline
\end{tabular}

D.M.S. (Tukey) a 5\% $\overline{\mathrm{mE}}=2,2 \overline{\mathrm{mF}}=1,2 \quad \mathrm{EF}=3,9 \quad \mathrm{FE}=3,1$

1. Médias com letras maiúsculas diferentes na mesma linha di ferem estatisticamente entre si,

2. Médias com letras minúsculas diferentes na-mesma coluna di ferem estatisticamente entre si.

\begin{tabular}{|c|c|c|}
\hline FONTE DE VARIAÇÃO & GL & $F$ \\
\hline $\begin{array}{l}\text { Epocas (E) } \\
\text { Fontes (F) } \\
\text { Interação E X } \quad F \\
\text { Residuo }\end{array}$ & $\begin{array}{r}6 \\
2 \\
12 \\
63\end{array}$ & $\begin{array}{c}161,0 *^{*} \\
3.594,37 * \\
45,14 *\end{array}$ \\
\hline & $\mathrm{CV} \%=$ & 4,9 \\
\hline $\begin{array}{l}\text { Epocas dentro ST } \\
\text { Epocas dentro YO } \\
\text { Epocas dentro YS }\end{array}$ & $\begin{array}{l}6 \\
6 \\
6\end{array}$ & $\begin{array}{c}1,10 \mathrm{n} . \mathrm{s} . \\
76,26^{*} \\
174,29^{*}\end{array}$ \\
\hline
\end{tabular}

$\begin{array}{lll}\text { Fontes dentro época } & 1 \\ \text { Fontes dentro época } & 2 \\ \text { Fontes dentro época } & 3 \\ \text { Fontes dentro época } & 4 \\ \text { Fontes dentro época } & 5 \\ \text { Fontes dentro época } & 6 \\ \text { Fontes dentro época } & 7\end{array}$

$1.406,14 *$

$1.181,02 *$

$1.334,41 *$

$1.007,44^{*}$

$771,88 *$

$1.020,78$ *

357,91 *

1. Significativo ao nivel de $5 \%$.

2. Não significativo. 


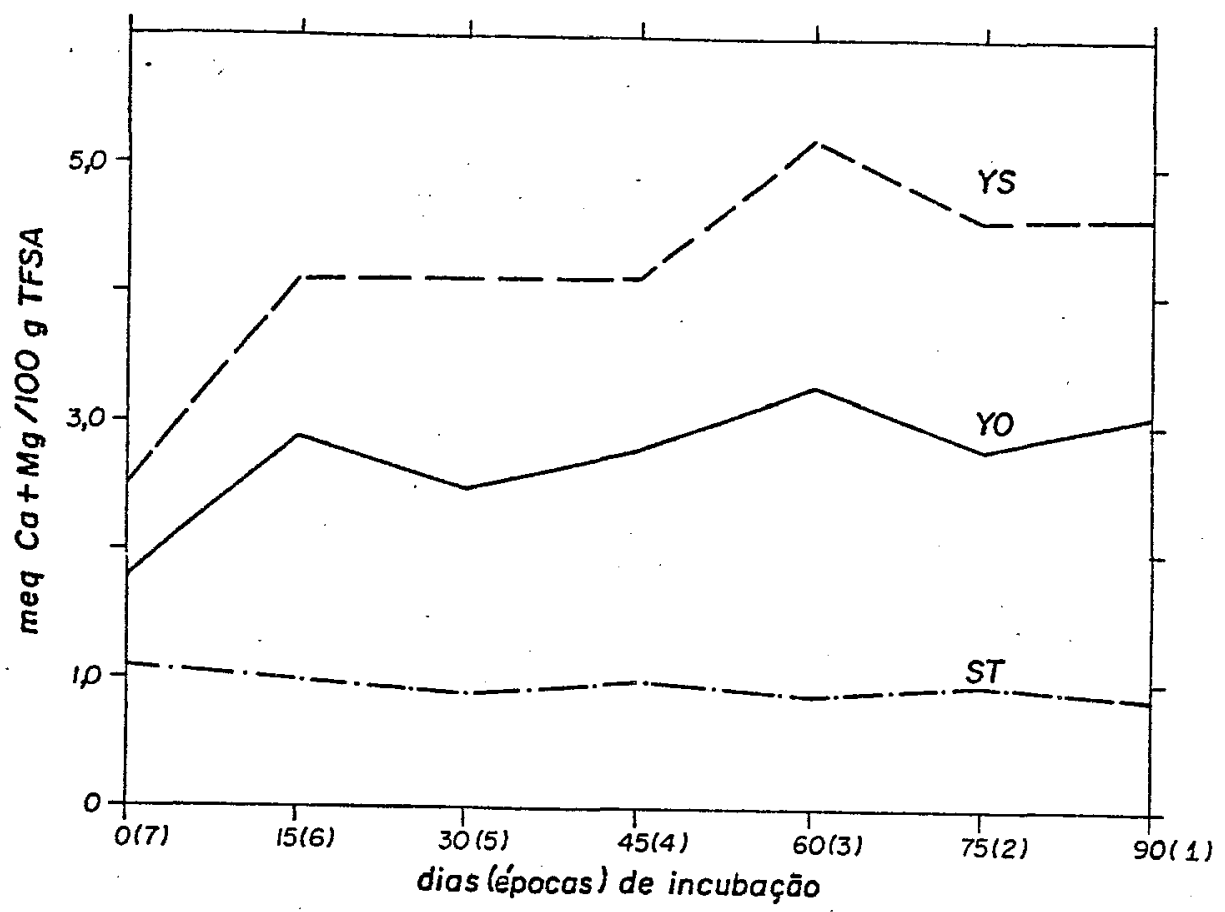

Figura 4. Teores de cálcio e magnésio no solo.

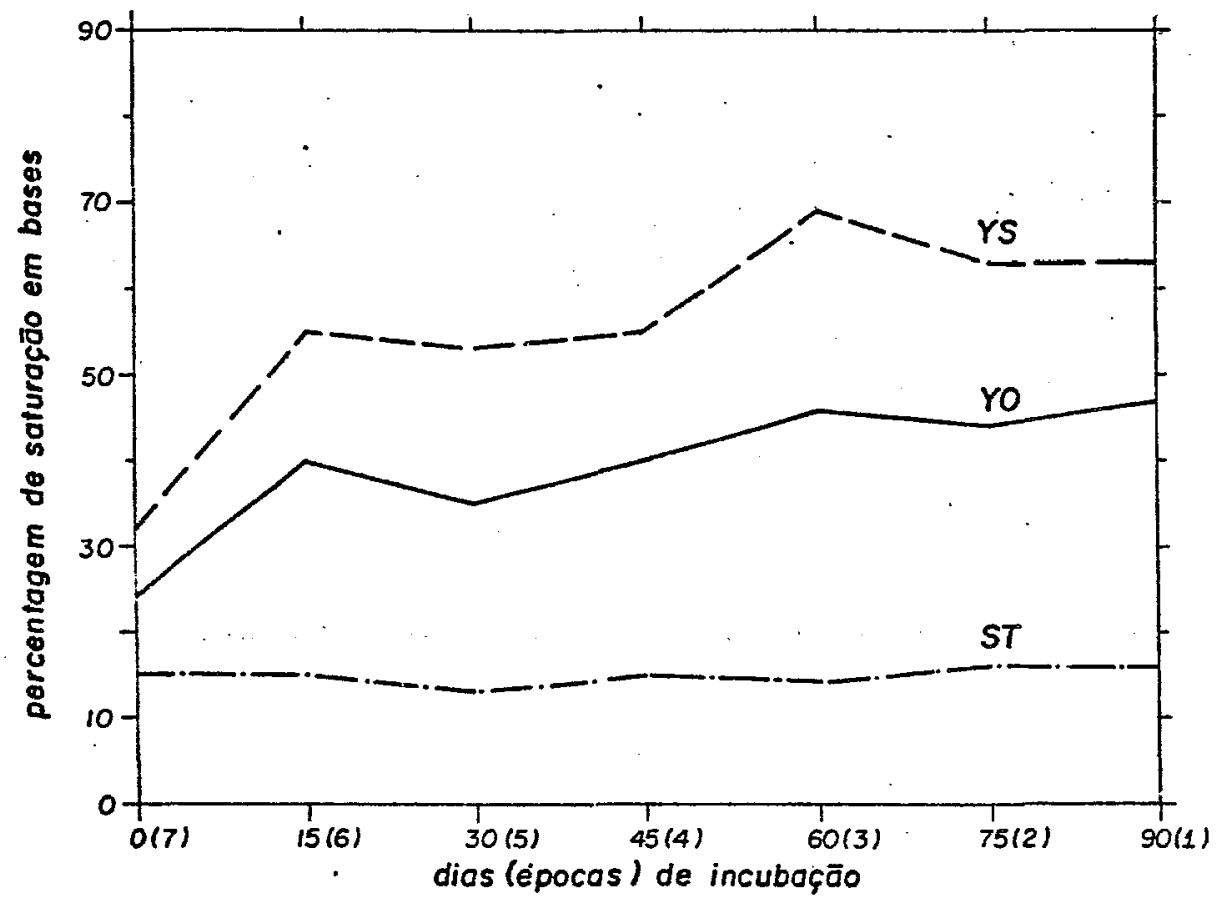

Figura 5. Porcentagem de saturação de bases no solo. 
Tanto para pH como para teor de $\mathrm{Ca}+\mathrm{Mg}$ e porcentagem de saturação de bases no solo, a fonte Ys apresentou sempre indices estatısticamente superiores aos obtidos com a aplicação de Yo.

Houve diferenças na acidez potencial comparando-se as três fontes (Tabela 8) sendo que Yo e YS apresentaram menores valores. Estas diferenças podem estar relacionadas aos materiais silicatados corretivos de acidez, sendo que o Ys por possuir maior teor de silicio, está demonstrando melhor efeito, chegando a diminuir atē a metade do valor inicial como verificado nas épocas 3 (60 dias de incubação). Como o pH é reflexo do conteúdo de bases de so 10, é de se esperar que exista uma estreita correlação entre - pH e o grau de saturação de bases do solo (CATANI \& GALLO, 1955). Em vista disto, para compreender as inter-relações que existem entre cátions trocáveis e pH em solos foi feita a correlação entre fontes (Figura 6). Constatou-se uma corre lação linear dada aproximadamente a esta equação:

$$
\mathrm{pH}=0,03176 \mathrm{~V}+4,288
$$

confirmando os estudos por CATANI \& GALLO (1955). 
Tabela 8. Valores da acidez potencial obtidos em amostras de terra após diferentes tempos de incubação para 3 fontes de fósforo.

\begin{tabular}{|c|c|c|c|c|c|c|c|c|c|}
\hline \multirow[b]{2}{*}{$\begin{array}{l}\text { FONTE } \\
\text { (F) }\end{array}$} & \multirow[b]{2}{*}{$\begin{array}{l}\text { EPOCA (E) } \\
\text { DIAS }\end{array}$} & \multicolumn{8}{|c|}{ Acidez Potencial } \\
\hline & & $7(0)$ & $6(15)$ & $5(30)$ & $4(45)$ & $3(60)$ & $2(75)$ & $1(90)$ & $\mathrm{m} F$ \\
\hline & ST & $5,88 \mathrm{ABa}$ & $5,90 \mathrm{ABa}$ & $6,20 \mathrm{Aa}$ & $\mathrm{q}_{5,52 \mathrm{BCa}}^{\mathrm{H}+\mathrm{A} 1 /}$ & $\begin{array}{l}/ 100 \mathrm{~g} \text { TFS } \\
5,48 \mathrm{BCa}\end{array}$ & $5,40 \mathrm{BCa}$ & $5,10 \mathrm{Ca}$ & $5,64 \mathrm{a}$ \\
\hline & Yo & $5,65 \mathrm{Aab}$ & 4,35 BCEls & $4,65 \mathrm{Bb}$ & $4,18 \mathrm{BCDb}$ & $4,0 \mathrm{CCDb}$ & $3,68 \mathrm{DEb}$ & $3,38 \mathrm{~Eb}$ & $4,27 b$ \\
\hline & YS & $5,38 \mathrm{Ab}$ & $3,38 \mathrm{Bc}$ & $3,62 \mathrm{Bc}$ & $3,35 \mathrm{BC}$ & $2,38 \mathrm{Cc}$ & $2,72 \mathrm{Cc}$ & $2,72 \mathrm{Cc}$ & $3,36 \mathrm{c}$ \\
\hline & $\overline{\mathrm{m}} \mathrm{E}$ & $5,63 \mathrm{~A}$ & $4,54 B C$ & $4,82 B$ & $3,95 D$ & $3,93 \mathrm{D}$ & $3,73 \mathrm{D}$ & $3,73 D$ & \\
\hline
\end{tabular}

D.M.S. (Tukey) a $5 \% \overline{\mathrm{mE}}=0,34 \quad \overline{\mathrm{mF}}=0,18 \mathrm{EF}=0,59 \mathrm{FE}=0,46$

1. Médias com letras maiúsculas diferentes na mesma linha di ferem estatisticamente entre si.

2. Médias com letras minúsculas diferentes na mesma coluna diferem estatisticamente entre si.

\begin{tabular}{|c|c|c|}
\hline FONTE DE VARIAÇÃO & GL & $F$ \\
\hline $\begin{array}{l}\text { Epocas }(\mathrm{E}) \\
\text { Fontes (F) } \\
\text { Interação E X F } \\
\text { Residuo }\end{array}$ & $\begin{array}{r}6 \\
2 \\
12 \\
63\end{array}$ & $\begin{array}{l}69,45 *^{1} \\
493,52 * \\
10,16 *\end{array}$ \\
\hline & $\mathrm{CV}$ 응 $=$ & 6,2 \\
\hline $\begin{array}{l}\text { Epocas dentro ST } \\
\text { Epocas dentro Yo } \\
\text { Epocas dentro YS }\end{array}$ & $\begin{array}{l}6 \\
6 \\
6\end{array}$ & $\begin{array}{r}7,40 * \\
29,48 * \\
52,90 *\end{array}$ \\
\hline $\begin{array}{lll}\text { Fontes dentro época } & 1 \\
\text { Fontes dentro época } & 2 \\
\text { Fontes dentro época } & 3 \\
\text { Fontes dentro época } & 4 \\
\text { Fontes dentro época } & 5 \\
\text { Fontes dentro época } & 6 \\
\text { Fontes dentro época } & 7\end{array}$ & $\begin{array}{l}2 \\
2 \\
2 \\
2 \\
2 \\
2 \\
2\end{array}$ & $\begin{array}{r}80,94 * \\
98,81 * \\
129,19 * \\
64,78 * \\
90,30 * \\
87,12 * \\
3,37 *\end{array}$ \\
\hline
\end{tabular}

1. Significativo ao nivel de $5 \%$ 


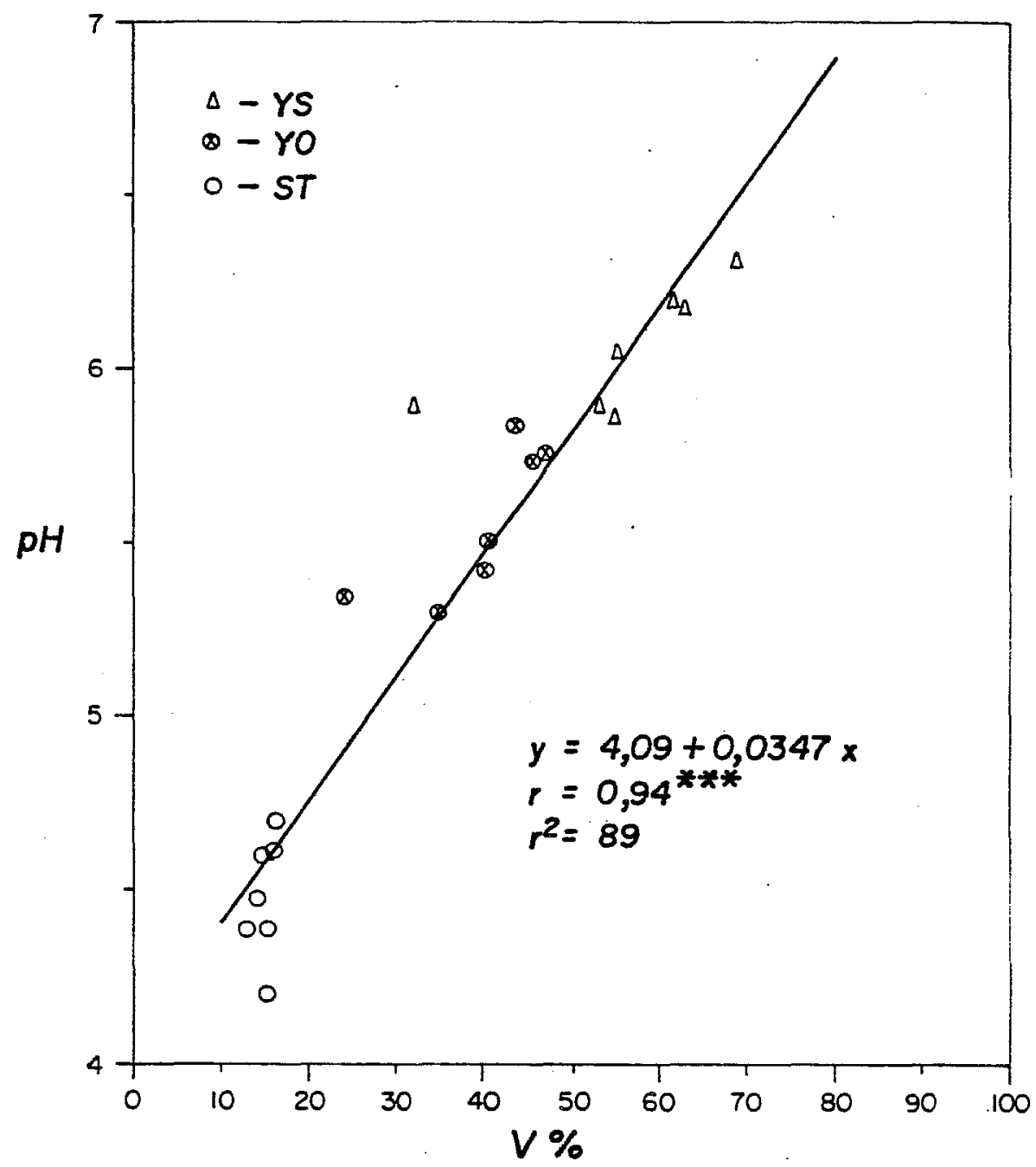

Figura 6. Relação entre porcentagem de saturação de bases e pH para todos os tratamentos.

4.2. Produção de matéria seca, absorção de $P$ e bases trocáveis

4.2.1. Produção de matéria seca

A maior produção de matéria seca, quando se 
utilizou a fonte ys pode ser explicado pela maior quantidade de fósforo extraído (Tabela 2 e Figura 1) além dos fatores relacionados à elevação do pH. Entretanto embora não houvesse diferença entre as fontes Yo e ST quanto à quantidade de fósforo disponível $\mathrm{H}_{2} \mathrm{SO}_{4} 0,05 \mathrm{~N}$ (Tabela 2 e Figura 1), a pro dução de matéria seca quando se utilizou a fonte yo foi estą tisticamente superior à obtida com ST (Tabela 9 e Figura 7), sugerindo que essas diferenças podem ser atribuidas aos fato res relacionados à reação do solo. Dentre estes fatores pode-se considerar o efeito corretivo da acidez do solo promovida pela aplicação tanto de YS como de Yo (Tabela 6 e Figura 2) fontes que apresentam silicatos nas suas composições, mantendo condições de reação do solo mais adequados ao desen volvimento da planta, enquanto os valores de $\mathrm{pH}$ no solo com a aplicação de ST.se manteve num nível bastante inferior. Es te efeito de mudança de $\mathrm{pH}$ concorda com os dados obtidos por NAKAGAWA et alii (1983). SILVA, et alii “. (1977), estudando por seis anos agricolas sucessivos com superfosfatos e termofosfatos concorreram para estabilizar o indice de $\mathrm{pH}$ e elevar o nível de magnésio no solo, além do teor do próprio fósforo. Um outro fator pode estar associado ao maior desenvolvimento vegetativo das fontes com silicato em relação ao ST, vem a ser o provável aumento na eficiência do aproveitamento de fósforo pela planta na presença de Si. De acordo com HINGSTON et alii, 1968 e 1972, a insolubilização de fósforo è reduzida na presença de $\mathrm{Si}$, em razão da competição entre 
osānions silicato e fosfato pelos sitios de adsorção do so10. Resultados semelhantes foram obtidos também por OBIHARA \& RUSSEL (1972) \& RAUPACH \& PIPER (1959). Para este experimento o teor de silica do YS aplicado foi de duas vezes maior em relação ao yo.

\subsubsection{Absorção de $P$}

o comportamento do fósforo foi analisada em termos de valores percentuais e quantidade de $\mathrm{P}(\mathrm{mg} / \mathrm{vaso})$ cu彑 jos resultados encontram-se nas Tabelas 10 e 11 , respectivamente. O fósforo foi melhor aproveitado pela planta quando a fonte utilizada foi o YS, com $31 \mathrm{mg} P /$ vaso contra $18 \mathrm{mg} P / \mathrm{va}$ so do YO em $4 \mathrm{mg}$ P/vaso do ST, com diferenças significativas entre eles. Porém, este resultado obtido pelo ys está abaixo dos valores encontrados por Fernandes et alii (1971) citado por MALAVOLTA et alii (1974) que foi de 46,9 mg P/vaso, para - mesmo periodo de colheita. GARCIA et alii (1988) também en contraram valores maiores do que YS apresentou neste ensaio, com aproximadamente $70 \mathrm{mg} \mathrm{P} /$ vaso para um periodo de 62 dias de idade. Avaliando-se as diferentes épocas em que o Ys foi aplicado, nota-se que o fósforo foi melhor aproveitado aos 60 dias de incubação. Os valores percentuais de $P$ na matéria seca confirmam os melhores resultados obtidos pelo YS, quando foi analisado em termos de valores totais por vaso. Porém este resultado também está abaixo do valor encontrado por 


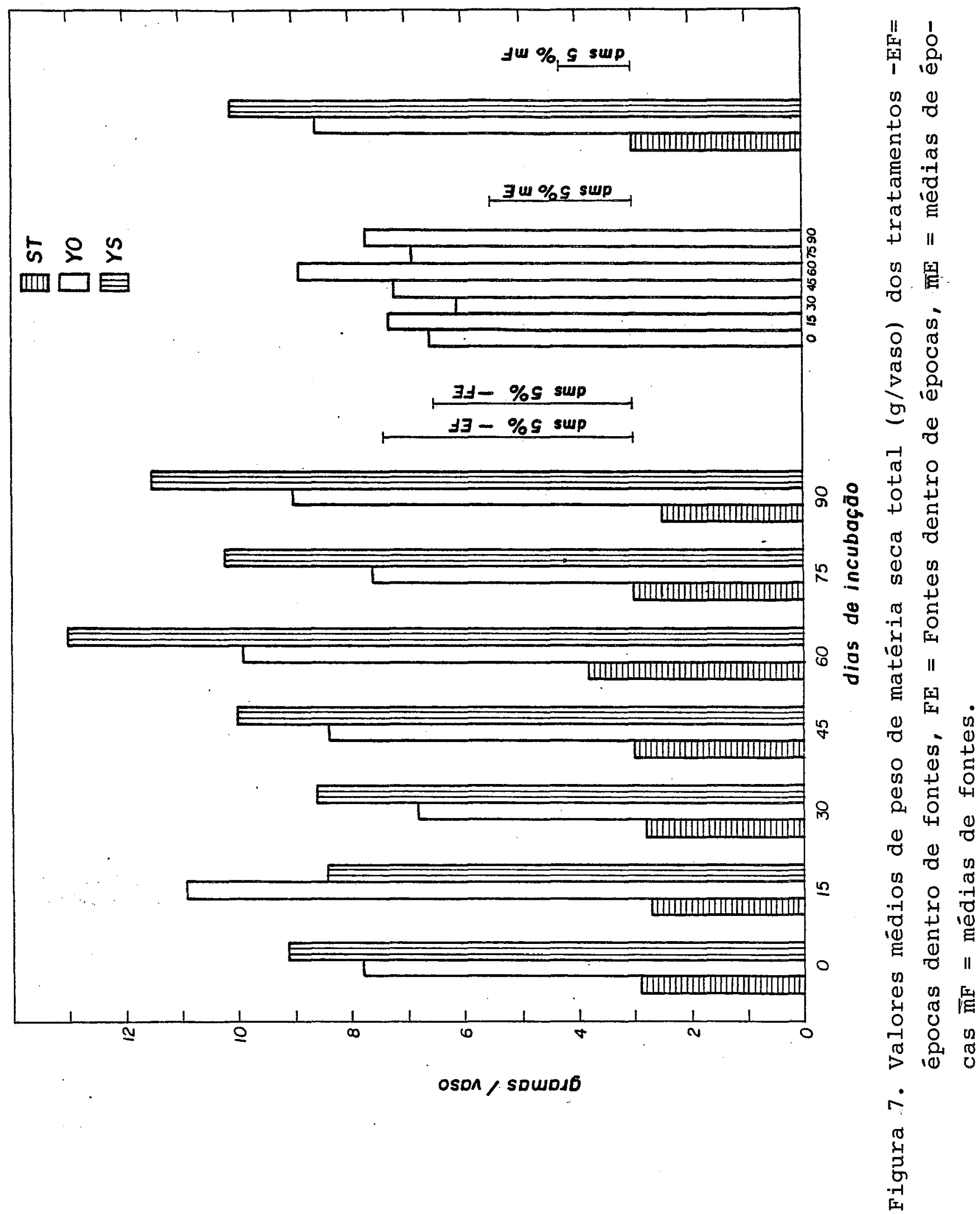


Tabela 9. Peso de matéria seca total obtidas de plantas cultivadas em diferentes tempos de incubação para 3 fontes de fósforo.

Peso da matéria seca total

\begin{tabular}{|c|c|c|c|c|c|c|c|c|c|}
\hline $\begin{array}{r}\text { FONTE } \\
(\mathrm{F}) \\
\end{array}$ & $\begin{array}{c}\text { EPOCA(E) } \\
-\quad \text { DIAS } \\
\end{array}$ & $7(0)$ & $6(15)$ & $5(30)$ & $4(45)$ & $3(60)$ & $2(75)$ & $1(90)$ & $\overline{\mathrm{m} F}$ \\
\hline & $\cdots$ & $-\infty=-$ & $=-----0-5$ & 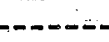 & g/vaso- & $--m-n$ & 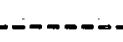 & - & $--\infty-\infty$ \\
\hline ST & & 2,9 & 2,7 & 2,8 & 3,0 & 3,8 & 3,0 & 2,5 & $3,0 \mathrm{c}$ \\
\hline YO & & 7,8 & 10,9 & 6,8 & 8,4 & 9,9 & 7,6 & 9,0 & $8,6 \mathrm{~b}$ \\
\hline YS & & 9,1 & 8,4 & 8,6 & 10,0 & 13,0 & 10,2 & 11,5 & $10,1 a$ \\
\hline$\overline{\mathrm{m}} E$ & & $6,6 \mathrm{AB}$ & $7,3 \mathrm{AB}$ & $6,1 B$ & $7,2 \mathrm{AB}$ & $8,9 A$ & $6,9 \mathrm{AB}$ & $7,6 \mathrm{AB}$ & \\
\hline
\end{tabular}

D.M.S. (Tukey) a $5 \frac{0}{\mathrm{~m}} \mathrm{E}=2,5 \quad \overline{\mathrm{m} F}=1,3 \quad \mathrm{EF}=4,4 \quad \mathrm{FE}=3,5$

1. Médias com letras maiúsculas diferentes na mesma linha di ferem estatisticamente entre si.

2. Médias com letras minúsculas diferentes na mesma coluna - diferem estatisticamente entre si.

Epocas (E)

6

$2,25 *^{1}$

Fontes (F)

2

96,18 *

Interação $E \times F$

12

1,23 n.s. ${ }^{2}$

Residuo

63

1. Significativo ao nivel de $5 \%$

2. Não significativo. 
Tabela 10. Porcentagem de fósforo na matéria seca obtidas de plantas cultivadas em diferentes tempos de incuba ção para 3 fontes de fósforo.

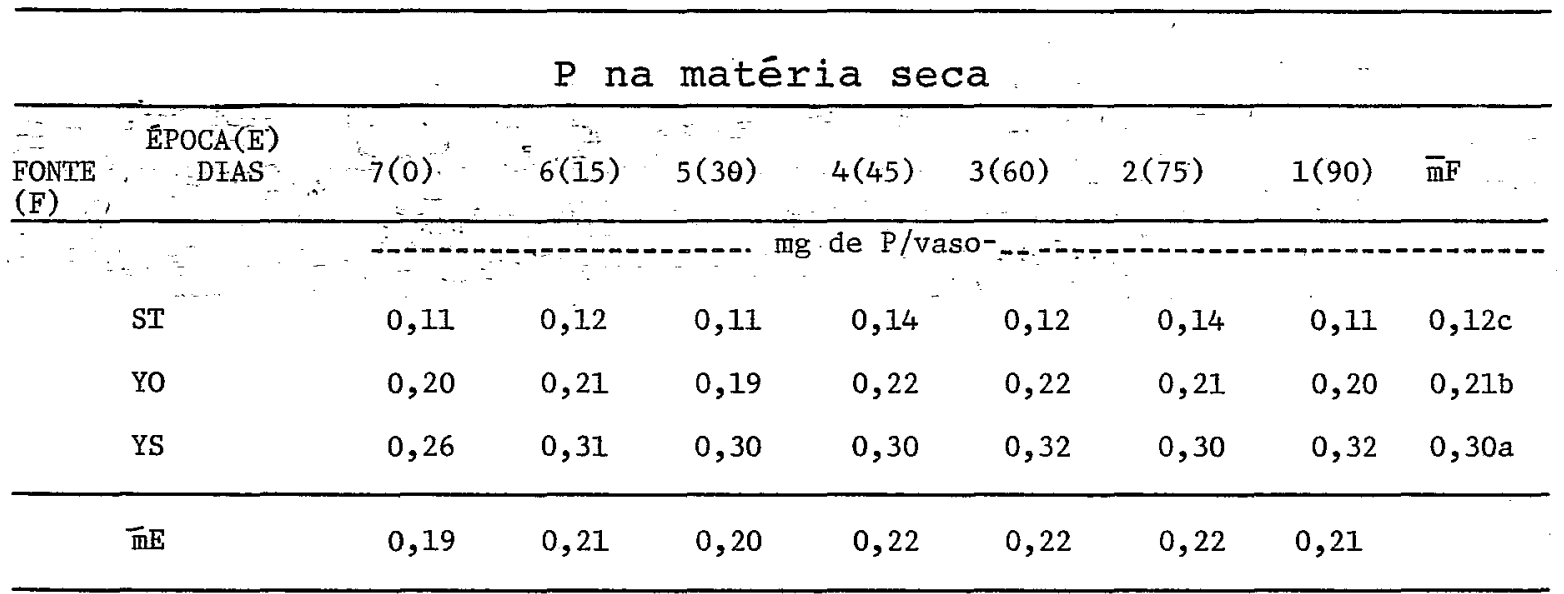

D.M.S. (Tukey) a $5 \% \overline{\mathrm{m}}=0,04 \overline{\overline{\mathrm{m}}}=0,02 \quad \mathrm{EF}=0,07 \quad \mathrm{FE}=0,05$

1. Médias com letras maiúsculas diferentes na mesma linha di ferem estatisticamente entre si.

2. Médias com letras minúsculas diferentes na mesma coluna diferem estatisticamente entre si.

FONTE DE VARIAÇÃO

Epocas (E)

Fontes (F)

Interação E X F

Residuo
GI $\quad$ F

6

$1,84 \mathrm{n.s.}{ }^{2}$

2

$244,31 *^{1}$

12

0,60 n.s.

63
14,5

1. Significativo ao nível de $5 \%$.

2. Não significàtivo. 
Tabela 11. Quantidade de fósforo absorvido pelas plantas cul tivadas em diferentes tempos de incubação para 3 fontes de fósforo.

\section{P absorvido}

\begin{tabular}{|c|c|c|c|c|c|c|c|c|c|}
\hline $\begin{array}{l}\text { FONTE } \\
\text { (F) }\end{array}$ & $\begin{array}{c}\text { EPOCA (E) } \\
\text { DIAS }\end{array}$ & $7(0)$ & $6(15)$ & $5(30)$ & $4(45)$ & $3(60)$ & $2(75)$ & $1(90)$ & $\overline{\mathrm{m}} \mathrm{F}$ \\
\hline & ST & 3 & 3 & 3 & 4 & 4 & 4 & 3 & $4 c$ \\
\hline & 10 & 16 & 23 & 13 & 20 & 21 & 16 & 18 & $18 \mathrm{~b}$ \\
\hline & YS & 24 & 26 & 25 & 30 & 41 & 30 & 37 & $31 a$ \\
\hline & $\bar{n} E$ & $14 \mathrm{~B}$ & $18 \mathrm{AB}$ & $14 \mathrm{~B}$ & $18 \mathrm{AB}$ & $22 \mathrm{~A}$ & $17 \mathrm{AB}$ & $19 \mathrm{AB}$ & \\
\hline
\end{tabular}

D.M.S. (Tukey) a 5\% $\overline{\overline{\mathrm{m}}} \mathrm{E}=8 \quad \overline{\overline{\mathrm{m}}} \mathrm{F}=4 \quad \mathrm{EF}=14 \quad \mathrm{FE}=11$

1. Médias com letras maiúsculas diferentes na mesma linha di ferem estatisticamente entre si.

2. Médias com letras minúśculas diferentes na mesma coluna diferem estatisticamente entre si.

Epocas (E)

Fontes (F)

Interação $\mathrm{E} \times \mathrm{F}$

Residuo
6

2

12

63

1. Significativo ao nivel de 5\%.

2. Não significativo. 
GARCIA et alii (1988) que foi de 0,8 a 0,92. Estes resultados podem estar relacionados ao maior valor de $\mathrm{pH}$ alcançado com a aplicação de Y̌s, que foram sempre maiores que as outras fontes, independentes de época de incủbação, conforme mostra a Tabela 6 e Figura 2 .

\subsubsection{Absorção de $\mathrm{Ca}^{+2}, \mathrm{Mg}^{+2} \mathrm{e}^{+}$}

os valores percentuais e os valores médios de quantidade de cálcio absorvida pela planta encontrados na matéria seca estão contidos nas Tabelas 12 e 13 respectivamente. O YS novamente apresentou melhores resultados, sendo que aos 60 dias houve maior absorção do elemento, porém em termos percentuais não houve diferenças significativas entre os periodos de incubação. Com relação à quantidade de Mg absorvida (mg de Mg/vaso) encontrados neste ensaio (Tabela 14), mostram serem superiores aos valores encontrados por GARCIA et alii (1988) e Fernandes et alii (1974), citado por MALAVOLTA et alii (1974) quando a fonte foi o YS. No caso do yo, os valores encontrados neste ensaio são semelhantes aos citados por estes mesmos autores. Interessante notar o fato de que o tratamento com YS apresentou maior quantidade de Mg absorvido pela cultura, uma vez que o yo contém maior porcen tagem deste elemento em sua composição. Uma provável explicą ção para este fato talvez se deva ao maior teor de Si em sua composição, já argumentado anteriormente. De modo semelhante 
Tabela 12. Porcentagem de cālcio na matéria seca obtidas de plantas cultivadas em diferentes tempos de incuba ção para 3 fontes de fósforo.

Ca na matéria seca

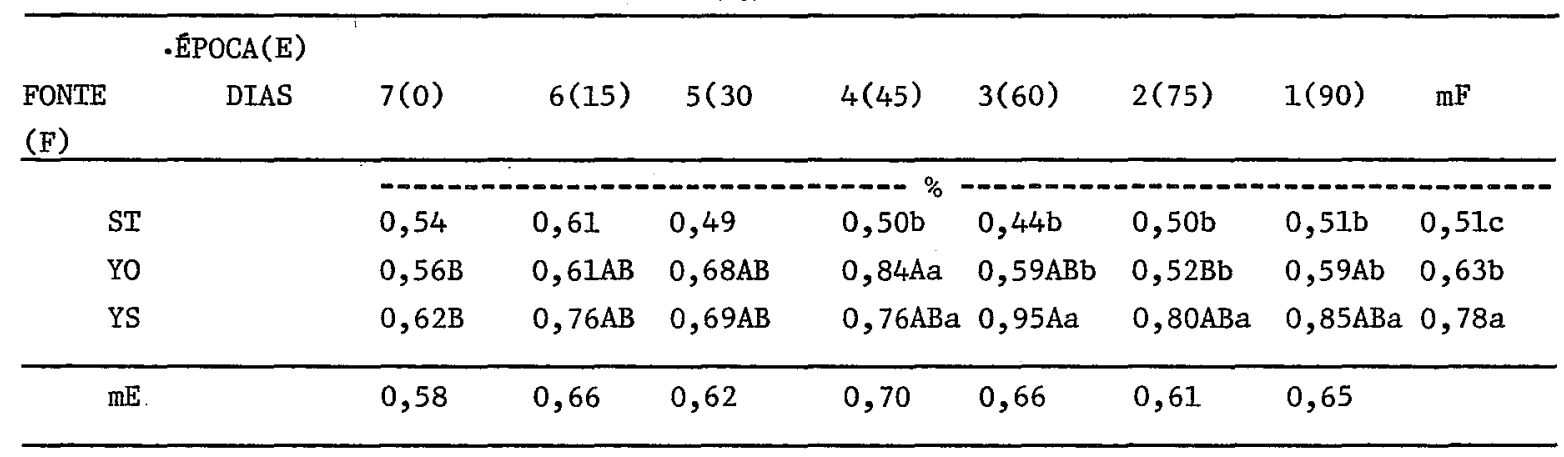

D.M.S. (Tukey) a $5 \% \mathrm{mE}=--\mathrm{mF}=0,08 \quad \mathrm{EF}=0,27 \quad \mathrm{FE}=0,21$

1. Médias com letras maiúsculas diferentes na mesma linha di ferem estatisticamente entre si.

2. Médias com letras minúsculas diferentes na mesma coluna di ferem estatisticamente entre si.

\begin{tabular}{|c|c|c|}
\hline FONTE DE VARIAÇÃO & GL & $F$ \\
\hline $\begin{array}{l}\text { Epocas }(E) \\
\text { Fontes (F) } \\
\text { Interação E x F } \\
\text { Residuo }\end{array}$ & $\begin{array}{r}6 \\
2 \\
12 \\
63\end{array}$ & $\begin{array}{l}1,29 n \cdot \mathrm{n}^{2} \\
30,78 * 1 \\
2,46 *\end{array}$ \\
\hline & $C V \%=$ & 19,8 \\
\hline $\begin{array}{l}\text { Epocas dentro ST } \\
\text { Epocas dentro YO } \\
\text { Epocas dentro YS }\end{array}$ & $\begin{array}{l}6 \\
6 \\
6\end{array}$ & $\begin{array}{l}0,78 \mathrm{n} . \mathrm{s} . \\
2,69 * \\
2,81 *\end{array}$ \\
\hline $\begin{array}{lll}\text { Fontes dentro época } & 1 \\
\text { Fontes dentro época } & 2 \\
\text { Fontes dentro época } & 3 \\
\text { Fontes dentro época } & 4 \\
\text { Fontes dentro época } & 5 \\
\text { Fontes dentro época } & 6 \\
\text { Fontes dentro época } & 7\end{array}$ & $\begin{array}{l}2 \\
2 \\
2 \\
2 \\
2 \\
2 \\
2 \\
2\end{array}$ & $\begin{array}{r}7,81 * \\
6,68 * \\
17,50 * \\
7,81 * \\
3,12 \text { n.s. } \\
1,88 \text { n.s. } \\
0,50 \text { n.s. }\end{array}$ \\
\hline
\end{tabular}

1. Significativo ao nivel de $5 \%$.

2. Não significativo. 
Tabela 13. Quantidade de cálcio absorvido pelas plantas cultivadas em diferentes tempos de incubação para 3 fontes de fósforo.

\section{Ca absorvido}

\begin{tabular}{|c|c|c|c|c|c|c|c|c|c|}
\hline \multirow[b]{2}{*}{$\begin{array}{l}\text { FONTE: } \\
(\mathrm{F})\end{array}$} & \multirow{2}{*}{$\begin{array}{c}\text { EPOCA(E) } \\
\text { DIAS }\end{array}$} & & & \multicolumn{4}{|c|}{$!$} & \multirow[b]{2}{*}{$\overline{\mathrm{m} F}$} \\
\hline & & $7(0)$ & $6(15)$ & $5(30)$ & $4(45)$ & $3(60)$ & $2(75)$ & $1(90)$ & \\
\hline & $\begin{array}{l}\text { ST } \\
\text { YO } \\
\text { YS }\end{array}$ & $\begin{array}{l}16 \mathrm{~b} \\
45 \mathrm{ab} \\
57 \mathrm{Ca}\end{array}$ & $\begin{array}{l}18 \mathrm{~b} \\
68 \mathrm{a} \\
64 \mathrm{BCa}\end{array}$ & $\begin{array}{l}14 \mathrm{~b} \\
46 \mathrm{ab} \\
59 \mathrm{BCa}\end{array}$ & $\begin{array}{l}\mathrm{de} C \mathrm{C} \\
16 \mathrm{~b} \\
74 \mathrm{a} \\
78 \mathrm{BCa}\end{array}$ & $\begin{array}{c}16 \mathrm{c} \\
58 \mathrm{~b} \\
123 \mathrm{Aa}\end{array}$ & $\begin{array}{l}15 \mathrm{~b} \\
39 \mathrm{~b} \\
82 \mathrm{ABCa}\end{array}$ & $\begin{array}{c}12 \mathrm{c} \\
54 \mathrm{~b} \\
100 \mathrm{ABa}\end{array}$ & $\begin{array}{l}15 c \\
.55 b \\
80 a\end{array}$ \\
\hline & $\overline{\mathrm{m}} \mathrm{E}$ & $39 B$ & $50 \mathrm{AB}$ & $40 B$ & $56 \mathrm{AB}$ & $66 \mathrm{~A}$ & $45 \mathrm{AB}$ & $55 \mathrm{AB}$ & \\
\hline
\end{tabular}

D.M.S. (Tukey) a 5\% $\overline{\bar{m}} E=24 \overline{\bar{m}} F=12 \quad E F=42 \quad F E=33$

1. Médias com letras maiúsculas diferentes na mesma linha di ferem estatisticamente entre si.

2. Médias com letras minúsculas diferentes na mesma coluna diferem estatisticamente entre si.

\begin{tabular}{|c|c|c|}
\hline FONTE DE VARIAÇÃO & GL & $F$ \\
\hline $\begin{array}{l}\text { Epocas }(\mathrm{E}) \\
\text { Fontes (F) } \\
\text { Interação E X F } \\
\text { Residuo }\end{array}$ & $\begin{array}{r}6 \\
2 \\
12 \\
63\end{array}$ & $\begin{array}{c}2,97 *^{1} \\
80,28 * \\
2,49 *\end{array}$ \\
\hline & - $\quad C V \%=$ & 38,7 \\
\hline $\begin{array}{l}\text { Epocas dentro ST } \\
\text { Epocas dentro YO } \\
\text { Epocas dentro YS }\end{array}$ & $\begin{array}{l}6 \\
6 \\
6\end{array}$ & $\begin{array}{l}0,04 \mathrm{n} . \mathrm{s} . \\
1,73 \mathrm{n} . \mathrm{s} . \\
6,18 *\end{array}$ \\
\hline $\begin{array}{lll}\text { Fontes dentro época } & 1 \\
\text { Fontes dentro época } & 2 \\
\text { Fontes dentro época } & 3 \\
\text { Fontes dentro época } & 4 \\
\text { Fontes dentro época } & 5 \\
\text { Fontes dentro época } & 6 \\
\text { Fontes dentro época } & 7\end{array}$ & $\begin{array}{l}2 \\
2 \\
2 \\
2 \\
2 \\
2 \\
2\end{array}$ & $\begin{array}{l}20,45^{*} \\
12,24^{*} \\
30,79 \\
12,93 \\
5,78 * \\
8,20 * \\
4,80^{*}\end{array}$ \\
\hline
\end{tabular}

1. Significativo ao nivel de $5 \%$.

2. não significativo. 
Tabela 14. Quantidade de magnésio absorvido pelas plantas cul tivadas em diferentes tempos de incubação para $\overline{3}$ fontes de fósforo.

Mg absorvido

\begin{tabular}{|c|c|c|c|c|c|c|c|c|c|}
\hline $\begin{array}{l}\text { FONTE } \\
\text { (F) }\end{array}$ & $\begin{array}{c}\text { EPOCA (E) } \\
\text { DIAS }\end{array}$ & $7(0)$ & $6(15)$ & $5(30)$ & $4(45)$ & $3(60)$ & $2(75)$ & $1(90)$ & $\mathrm{mF}$ \\
\hline
\end{tabular}

\begin{tabular}{lllllllll}
\hline $\mathrm{ST}$ & $8 \mathrm{~b}$ & $9 \mathrm{~b}$ & $7 \mathrm{~b}$ & $9 \mathrm{~b}$ & $11 \mathrm{~b}$ & $9 \mathrm{~b}$ & $7 \mathrm{c}$ & $9 \mathrm{c}$ \\
$\mathrm{YO}$ & $33 \mathrm{a}$ & $44 \mathrm{a}$ & $30 \mathrm{a}$ & $50 \mathrm{a}$ & $45 \mathrm{~b}$ & $30 \mathrm{~b}$ & $38 \mathrm{~b}$ & $39 \mathrm{~b}$ \\
$\mathrm{YS}$ & $40 \mathrm{Ca}$ & $44 \mathrm{BCa}$ & $46 \mathrm{BCa}$ & $49 \mathrm{BCa}$ & $85 \mathrm{Aa}$ & $61 \mathrm{ABCa}$ & $70 \mathrm{ABa}$ & $56 \mathrm{a}$ \\
\hline $\mathrm{mE}$ & $27 \mathrm{~B}$ & $32 \mathrm{AB}$ & $27 \mathrm{~B}$ & $36 \mathrm{AB}$ & $47 \mathrm{~A}$ & $33 \mathrm{AB}$ & $38 \mathrm{AB}$ \\
\hline
\end{tabular}

D.M.S. (Tukey) a $5 \% \mathrm{mE}=16 \quad \mathrm{mF}=8 \quad \mathrm{EF}=28 \quad \mathrm{FE}=22$

1. Médias com letras maiúsculas diferentes na mesma linha di ferem estatisticamente entre si.

2. Médias com letras minúsculas diferentes na mesma coluna diferem estatisticamente netre si.

\begin{tabular}{|c|c|c|}
\hline FONTE DE VARIAÇÃO & GL & $\mathbf{F}$ \\
\hline $\begin{array}{l}\text { Epocas (E) } \\
\text { Fontes (F) } \\
\text { Interação E X F } \\
\text { Residuo }\end{array}$ & $\begin{array}{r}6 \\
2 \\
12 \\
63\end{array}$ & $\begin{array}{c}3,42 * 1 \\
97,03 * \\
2,37 * \\
.\end{array}$ \\
\hline & $\mathrm{CV}$ 응 $=$ & $37,4 *$ \\
\hline $\begin{array}{l}\text { Epocas dentro ST } \\
\text { Epocas dentro YO } \\
\text { Epocas dentro YS }\end{array}$ & $\begin{array}{l}6 \\
6 \\
6\end{array}$ & $\begin{array}{l}0,05 \mathrm{n} \cdot \mathrm{s} \cdot{ }^{2} \\
1,64 \mathrm{n} \cdot \mathrm{s} \cdot 2 \\
6,48 *\end{array}$ \\
\hline $\begin{array}{lll}\text { Fontes dentro época } & 1 \\
\text { Fontes dentro época } & 2 \\
\text { Fontes dentro época } & 3 \\
\text { Fontes dentro época } & 4 \\
\text { Fontes dentro época } & 5 \\
\text { Fontes dentro época } & 6 \\
\text { Fontes dentro época } 7\end{array}$ & $\begin{array}{l}2 \\
2 \\
2 \\
2 \\
2 \\
2 \\
2\end{array}$ & $\begin{array}{l}23,47 * \\
16,30 * \\
32,79 * \\
13,40 * \\
9,20 * \\
9,65 * \\
6,45 *\end{array}$ \\
\hline
\end{tabular}

1. Significativo ao nivel de 5\%.

2. Não significativo 
ao comportamento observado para cálcio, o magnésio também apresentou maior quantidade absorvida aos 60 dias (Tabela 14), porém percentualmente não apresentando diferenças estatisticas entre as diferentes épocas (Tabela 15).

No caso do potássio, tanto na porcentagem como na quantidade absorvida da matéria seca (Tabela 16 e 17, res pectivamente) $\circ$ YS $e \circ$ YO apresentaram resultados melhores que o ST. Convém lembrar que o fornecimento de potássio foi igual para todas as fontes, no entanto, este melhor aproveitamento do elemento pode ser atribuída à mudança do $\mathrm{pH}$ influ enciado pelos silicatos. 
Tabela 15. Porcentagem de magnésio na matéria seca obtida de plantas cultivadas em diferentes tempos de incuba ção para 3 fontes de fósforo.

\begin{tabular}{|c|c|c|c|c|c|c|c|c|c|}
\hline & & & g na ma & téria & seca & (g de & $\mathrm{Mg} / 100$ & $g \mathrm{~m} . \mathrm{s}$ & )$. \\
\hline \multirow[t]{5}{*}{$\begin{array}{l}\text { FONTE } \\
(\mathrm{F})\end{array}$} & $\begin{array}{c}\text { EPOCA (E) } \\
\text { DTAS }\end{array}$ & $7(0)$ & $6(15)$ & $5(30)$ & $4(45)$ & $3(60)$ & $2(75)$ & $1(90)$ & $\overline{\mathrm{m} F}$ \\
\hline & ST & $0,29 \mathrm{~b}$ & $0,32 \mathrm{~b}$ & $0,24 \mathrm{~b}$ & $0,28 b \%$ & $0,29 \mathrm{~b}$ & $0,30 \mathrm{~b}$ & $0,29 \mathrm{c}$ & $0,29 c$ \\
\hline & Yo & $0,42 \mathrm{Ba}$ & $0,44 \mathrm{Ba}$ & $0,58 \mathrm{Ba}$ & $0,58 \mathrm{Aa}$ & $0,46 \mathrm{ABb}$ & $0,40 \mathrm{Bb}$ & $0,42 \mathrm{Bb}$ & $0,44 \mathrm{~b}$ \\
\hline & YS & $0,44 \mathrm{Ca}$ & $0,52 \mathrm{ABCa}$ & $0,53 \mathrm{BCa}$ & $0,48 \mathrm{BCa}$ & $0,66 \mathrm{Aa}$ & $0,58 \mathrm{ABCa}$ & $0,60 \mathrm{ABa}$ & $0,54 a$ \\
\hline & $\overline{\mathrm{m}} \mathrm{F}$ & 0,38 & 0,41 & 0,41 & 0,45 & 0,47 & 0,42 & 0,44 & \\
\hline
\end{tabular}

D.M.S. (Tukey) a 5\% $\overline{\mathrm{m} E}-\overline{\mathrm{m}} \mathrm{F}=0,04 \quad \mathrm{EF}=0,15 \quad \mathrm{FE}=0,12$

1. Médias com letras maiúsculas diferentes na mesma linha di ferem estatisticamente entre si.

2. Médias com letras minúsculas diferentes na mesma coluna diferem estatisticamente entre si.

\begin{tabular}{|c|c|c|}
\hline FONTE DE VARIAÇÃO & GL & $F$ \\
\hline $\begin{array}{l}\text { Epocas }(\mathrm{E}) \\
\text { Fontes (F) } \\
\text { Interação E × F } \\
\text { Residuo }\end{array}$ & $\begin{array}{r}6 \\
2 \\
12 \\
63\end{array}$ & $\begin{array}{l}2,13 \mathrm{n} . \mathrm{s} .2 \\
98,60 * 1 \\
3,13 *\end{array}$ \\
\hline & $\mathrm{CV} \%=$ & 16,2 \\
\hline $\begin{array}{l}\text { Epocas dentro ST } \\
\text { Epocas dentro YO } \\
\text { Epocas dentro YS }\end{array}$ & $\begin{array}{l}6 \\
6 \\
6\end{array}$ & $\begin{array}{l}0,46 \mathrm{n} . \mathrm{s} . \\
3,42 * \\
4,52 *\end{array}$ \\
\hline $\begin{array}{lll}\text { Fontes dentro época } & 1 \\
\text { Fontes dentro época } & 2 \\
\text { Fontes dentro época } & 3 \\
\text { Fontes dentro época } & 4 \\
\text { Fontes dentro época } & 5 \\
\text { Fontes dentro época } & 6 \\
\text { Fontes dentro época } & 7\end{array}$ & $\begin{array}{l}2 \\
2 \\
2 \\
2 \\
2 \\
2 \\
2\end{array}$ & $\begin{array}{l}20,08^{*} \\
17,97^{*} \\
27,48^{*} \\
19,03^{*} \\
19,02^{*} \\
8,34^{*} \\
5,66^{*}\end{array}$ \\
\hline
\end{tabular}

1. Significativo ao nivel de $5 \%$

2. Não significativo. 
Tabela 16. Porcentagem de potássio na matéria seca obtida de plantas cultivadas em diferentes tempos de incuba ção por 3 fontes de fósforo.

K na matéria seca

\begin{tabular}{cccccccccc}
\hline \multirow{2}{*}{$\begin{array}{c}\text { EONTE } \\
\text { EFOCA(E) }\end{array}$} & DIAS & $7(0)$ & $6(15)$ & $5(30)$ & $4(45)$ & $3(60)$ & $2(75)$ & $1(90)$ & mF \\
\hline ST & & 2,05 & 1,96 & $1,71 \mathrm{c}$ & $1,79 \mathrm{~b}$ & $1,86 \mathrm{~b}$ & 1,92 & $1,61 \mathrm{~b}$ & $1,84 \mathrm{~b}$ \\
$\mathrm{YO}$ & $2, \overline{13}$ & $2,19 \mathrm{BC}$ & $3,50 \mathrm{Aa}$ & $3,08 \mathrm{ABa}$ & $2,66 \mathrm{ABCa}$ & $2,04 \mathrm{C}$ & $2,09 \mathrm{Cab}$ & $2,53 \mathrm{a}$ \\
$\mathrm{YS}$ & 2,09 & 2,21 & $2,68 \mathrm{~b}$ & $2,28 \mathrm{~b}$ & $2,78 \mathrm{a}$ & 2,51 & $2,70 \mathrm{a}$ & $2,46 \mathrm{a}$ \\
\hline $\mathrm{mE}$ & 2,09 & 2,12 & 2,63 & 3,38 & 2,13 & 2,16 & 2,13 \\
\hline
\end{tabular}

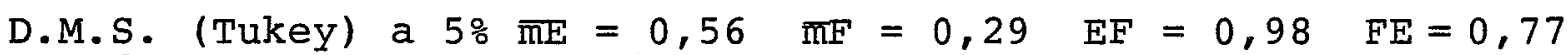
1. Médias com letras maiúsculas diferentes na mesma linha di ferem estatisticamente entre si.

2. Médias com letras minúsculas diferentes na mesma coluna di ferem estatisticamente entre si.

\begin{tabular}{|c|c|c|}
\hline FONTE DE VARIAÇÃO & GL & $\mathrm{F}$ \\
\hline $\begin{array}{l}\text { Epocas (E) } \\
\text { Fontes (F) } \\
\text { Interação E x F } \\
\text { Residuo }\end{array}$ & $\begin{array}{r}6 \\
2 \\
12 \\
63\end{array}$ & $\begin{array}{r}2,48 * 1 \\
19,45 * \\
2,87 *\end{array}$ \\
\hline & $\mathrm{CV} \%=$ & 19,9 \\
\hline $\begin{array}{l}\text { Epocas dentro ST } \\
\text { Epocas dentro YO } \\
\text { Epocas dentro YS }\end{array}$ & $\begin{array}{l}6 \\
6 \\
6\end{array}$ & $\begin{array}{l}0,44 \mathrm{n} . \mathrm{s} . \\
6,36^{*} \\
0,12 \mathrm{n} . \mathrm{s} .\end{array}$ \\
\hline $\begin{array}{lll}\text { Fontes dentro época } & 1 \\
\text { Fontes dentro época } & 2 \\
\text { Fontes dentro época } & 3 \\
\text { Fontes dentro época } & 4 \\
\text { Fontes dentro época } & 5 \\
\text { Fontes dentro época } & 6 \\
\text { Fontes dentro época } & 7\end{array}$ & $\begin{array}{l}2 \\
2 \\
2 \\
2 \\
2 \\
2 \\
2 \\
2\end{array}$ & $\begin{aligned} 5,73^{*} \\
1,87^{\mathrm{n}} . \mathrm{s} . \\
4,86^{*} \\
8,21^{*} \\
15,55^{*} \\
0,36 \mathrm{n} . \mathrm{s} . \\
0,29 \mathrm{n} . \mathrm{s} .\end{aligned}$ \\
\hline
\end{tabular}

1. Significativo ao nivel de 5\%.

2. Não significativo. 
Tabela 17. Quantidade de potássio absorvido pelas plantas cultivadas em diferentes tempos de incubação para 3 fontes de fósforo.

K absorvido

\begin{tabular}{|c|c|c|c|c|c|c|c|c|c|}
\hline \multicolumn{3}{|c|}{ EPOCA $(E)$} & \multirow[b]{2}{*}{$6(15)$} & \multirow[b]{2}{*}{$5(30)$} & \multirow[b]{2}{*}{$4(45)$} & \multirow[b]{2}{*}{$3(60)$} & \multirow[b]{2}{*}{$2(75)$} & \multirow[b]{2}{*}{$1(90)$} & \multirow[b]{2}{*}{$\overline{\mathrm{m} F}$} \\
\hline $\begin{array}{c}\text { FONTE } \\
(\mathrm{F})\end{array}$ & DIAS & $7(0)$ & & & & & & & \\
\hline 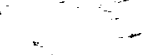 & & $=-$ & $-\cdots-c-$ & $\cdots$ & $--\%$ de & k/vaso- & 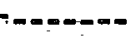 & $-\infty-2-\infty$ & - \\
\hline SI & & 60 & 53 & 48 & 54 & 70 & 55 & 40 & $54 \mathrm{~b}$ \\
\hline YC & & 166 & 237 & 231 & 250 & 256 & 169 & 195 & $215 a$ \\
\hline YS & & 192 & 188 & 225 & 228 & 370 & 257 & 309 & $253 a$ \\
\hline$\overline{\mathrm{m}}_{\mathrm{r}}$ & & 137B & $159 \mathrm{AB}$ & $168 \mathrm{AB}$ & $178 \mathrm{AB}$ & $232 \mathrm{~A}$ & $160 \mathrm{AB}$ & $182 \mathrm{AB}$ & \\
\hline
\end{tabular}

D.M.S. (Tukey) a 5\% $\overline{\mathrm{mE}}=80 \quad \overline{\mathrm{mF}}=41 \quad \mathrm{EF}=138 \quad \mathrm{FE}=109$

1. Médias com letras maiúsculas diferentes na mesma linha di ferem estatisticamente entre si.

2. Médias com letras minúsculas diferentes na mesma coluna di ferem estatisticamente entre si.

FONTE DE VARIAÇÃO

GL

F

\begin{tabular}{lcc}
\hline Epocas (E) & 6 & $2,47 *^{1}$ \\
Fontes (F) & 2 & $77,37 *$ \\
Interação E x F & 12 & $1,62 \mathrm{n.s.}{ }^{2}$ \\
Residuo & 63 & \\
\hline & CVo $=$ & 39,9 \\
\hline
\end{tabular}

1. Significativo ao nivel de $5 \%$.

2. Não significativo. 


\section{CONCLUSÕES}

Para as condições em que este trabalho de pesquisa foi realizado e com base nos dados obtidos, pode-se con cluir que:

- A fonte Yoosirin apresentou teores de fósfo ro disponivel no solo maiores que o Yoorin e o Superfosfato Triplo, sendo que estasipresentaramteores estatisticamente iguais.

- A aplicação das três fontes proporcionou vaIores de $\mathrm{pH}$ diferentes, no solo independente da época de incubação, sendo o Yoosirin maior que o Yoorin e esta maior que - Superfosfato Triplo.

- As produções de matēria seca obtidas com a aplicação das três fontes no cōmputo geral, diferiram entre si, sendo que o Yoosirin proporcionou maior produção que $\circ$ Yoorin e esta suplantou o Superfosfato Triplo. 


\section{BIBLIOGRAFIA CITADA}

ADAMS, J.P.; ADAMS, F.; ODOM, J.W. Interaction of phosphorus rate and soil pH ou soybean yield and soil solution composition of two phosphorus-sufficient ultisols. Soil Sci. Soc. Am. J., 46: 323-328, 1982.

AYRES, A. Calcium silicate slag as a growth stimulant for sugarcane on low-silicon soils. Soil Sci., 101: 216-217, 1966 .

BAIR, R.A. Leaf silicon in sugarcane, field corn and st. Augustine grass grown on some Florida soils. Proceed. Soil Crop. Sci. Soc. Fla., 26: 64-70, 1966.

BRAGA, J.M. \& AMARAL, F.A.L. Efeito de fontes de fósforo na variação do pH e disponibilidade de fósforo, cálcio e mag nèsio em um solo de Viçosa. Bragantia, Campinas, 18 (98): $326-335,1971$. 
BROWN, T.H.; MAHLER, R.L. Effects of phosphorus and acidity on levels of silica extrated from a Palouse silt loan. Soil Sci. Soc. of Ameri., Moscow; 51(3) p.671-677, 1987 .

CAMARGO, O.A.; MONIZ, A.C.; JORGE, J.A. \& VALADARES, J.M.A.S. Métodos de análise química, mineralógica e física desoilos do Instituto Agronômico de Campinas. Campinas, Instituto Agronômico, 1986, 94p. (Boletim Têcnico, 106).

CASTRO, D.M. Mineralogia de suelos. Bogotá, Instituto Geográfico Agustin Codazzi. v.11, 828p., 1975.

CARVALHO, W.A.; ESPINDOLA, C.R; PACCOLA, A.A. Levantamento de solos da Fazenda Lageado-Estação Experimental "Presidente Médici". Botucatu, Fac. de Ciências Agronômicas, 1983, 95p. (Boletim Cientifico, 1).

CATANI, R.A. \& GALLO, J.R. Avaliação da exigência de calcário dos solos do Estado de são Paulo mediante a correlação entre $\mathrm{pH}$ e a saturação em bases. Revista de Agricultura. $30=49-60,1955$.

CATANI, R.A.; GALLO, R.J.: GARGANTINI, H. Amostragem de so los, mētodos de anālise, interpretação e indicação gerais para fins de fertilidade. Campinas, Instituto Agronōmico, 1955. (Boletim Técnico 69). 
CLEMENTS, H.F. Effects of silicate on the growth and leaf freckle of sugarcane in Hawaii. Proc. Int. Sugar Cane Tech., puerto Rico, 12: 197-215, 1967.

DEWAN, M. \& HUNTER, A.S. Absorption of phosphorus by soybean and sudan grass. II. Effect of silicates. Soil Sci., 68: $479-482,1949$.

DONG, C.T.; LIU, Z.G.; ZON, B.L.; ZHU, C.; ZHANG, C.I.; LIANG, W. Effect of zinc and silicon on increasing rice yield Liaoning Agricultural Science, China, no 4, 1981, p.13-18.

EMBRAPA - Empresa Brasileira de Pesquisa Agropecuária. Centro de Pesquisa Agropecuária dos Cerrados. Relatório, téc nico anual, Planaltina, DF. 1978-1979, 170p.

ESTEBAN, E.; ROBLES, J.; GALLARDO-LARA; F. Silicon concentration effect on plant nutrition. In: PROCEEDINGS,VI th, INTERNATIONAL COLLOQUIUM FOR THE OPTIMIZATION OF PLANT NUTRITION, MONTPELIER, V.1, p.181-187, 1984.

GARCIA, L.L.C.; HAAG, H.P.; MINAMI, K.; DECHEN, A.R. Nutr $\underline{i}$ ção mineral de hortaliças: concentração e acúmulo de macronutrientes em alface (Lactuca sativa L.) Cv. Brasil 48 e Clause's Aurelia. In: HAAG, H.P. e MINAMI, K. Nutrição mineral em hortaliças, Campinas, Fundação Cargill, 1988, p. 123-151. 
GOEDERT, W.J.\& LOBATO, E. Avaliação agronômica de fosfatos em solos de cerrados. R. bras. Ci. Solo, 8: 97-102, 1984 .

GOMES, F.P. A estatistica moderna na pesquisa agropecuária, Piracicaba, POTAFÓS, 1984, 106p.

GURGEL, M.N.A. Efeitos do silicato e cālcio e a sua interação como o fósforo no estado nutricional, produtividade e qualidade tecnológica da cana-de-açūcar (Saccharum sp.), Piracicaba, ESALQ/USP. 1979, 62p. (Mestrado).

HALAIS; P. \& PARISHI, D.H. Silica and Manganese content of cane sheats in relation to soil and nutrition. Mauritius Sugar. Ind. Res. Int. Annu. Rept. (1963): 74-76, 1963.

HINGSTON, F.J.; ATKINSON, R.J.; POSNER, A.M. ; QUIRK, J.P. Specific adsorption of the anions on goethite. In: INTERNATIONAL CONGRESS OF SOIL SCIENCE, 90. Proceedings. Baltimore Soil Science. v.1, p.669-678. 1968.

HINGSTON, F.J.; POSNER, A.M.; QUIRK, J.P. Anion adsorption by goethite and gibbsite. I. The role of the proton in determinning adsorption envelopes. J. Soil. Sci., Oxford, $23(2): 177-192,1972$. 
HUSZ, G.S. Sugar cane, cultivation and fertilization. Univer sity in Hobenbein, West Germany, Ruhr-Stickstoff, 1972. $116 \mathrm{p}$.

JACKSON, M.I. Análises químico de suelos. Ediciones Omega, Barcelona, $1964,662 \mathrm{p}$.

JONES, L.H.P. \& HANDRECK, K.A. Silica in soils, plants and animals. Advances in Agronomy, New York, 1967, p.107-149.

KAFKAFI, V. Hidrogen consuption and silica release during initial stages of phosphate adsorption on kaolinite at a constant pH. Isr. J. Chem., Pehovot, 6: 367-373, 1968 .

KHAN, D.H. \& ROY, A.C. Growth, P uptake and fibre cell dimensions of jute plant as affected by silicate treatment. Plant and Soil, 20: 331-336, 1964 .

KILMER, V.I. \& L.T. ALEXANDER, Method of making mechanical analisys of soil. Soil Sci., 68(1): 15-26.

LEWIN,J. \& REIMANN, E.F. Silicon and plant growth. Ann. Rev. Plant Physiol, 20: 289-304, 1969. 
LIN, H.C.; HUNG, J.J. Antagonistic an well an synergistic effect between $\mathrm{Si}$ and $\mathrm{P}$ in the nutrition of rice plant. Soil and Fertilizer in Taiwan. Taipai, 1980, p.1-11.

MALAVOLTA, E.; - Análise química dos teores totais. Cu so Internacional de Diagnose Foliar, Piracicaba, 36p. 1964.

MALAVOLTA, E.; HAAG, H.P.; DE MELLO, F.A.; BRASIL SOBRINHO, M.O.C. Nutrição mineral e adubação de plantas cultivadas. São Paulo, Ed. Pioneira, 1974, 752p.

MCKEAGUE, J.A. \& CLINE,M.G. Silica in Soils. Adv. Agron., $15: 339-389,1963$.

MENGEL, K. \& KIRKBY, E.A. Principles of plant nutrition. 3 ed. Bern, Internacional Potash Institute, 1982. 655p.

MIYAKE, Y \& TAKAHASHI. Effect of silicon on the growth of cucumber plant in soil culture. Soil Sci.. and plant Nutr.: Japan, $29(4)$ p. 463-471, 1983.

NAKAGAWA; J.; BULL, L.T.; BOARETTO, A.E.:; FELIPE, L.A. Ava liação do efeito do termofosfato na fertilidade de dois solos através do uso de métodos químico e biológico. R. Agric., Piracicaba, 58(3): 125-139, 1983. 
OBIHARA, C.H. \& RUSSEL, E.W. Specific adsorption of silicate and phosphate by soils. J. of Soil Sci., 23: 105-107, 1972 .

OKUDA, A. \& TAKAHASHI. The role of silicon. In: HOPKINS, J. ed. The mineral nutrition of rice plant. Baltimore, 'p. $123-144,1964$.

OLIVEIRA, M.G.A. Determinação, adsorção e deslocamento recí proco de silício e fósforo em latossolos do Triângulo Mineiro. Viçosa, UFV, Impr. Univ., 1984. 68p. (Tese M.S.) .

PARRY, R.W.; HODSON, M.J.; SANGSTER, A.G. Some recent advances in studies of silica in higher plants. Phyl. Trans. of.. the Royal Soci. of London, Bangor, $304 \mathrm{p}$. $537-549,1984$.

PLUCKNETT, D.L. The use soluble silicate in Hawaiian agricul ture. Univ. of Queensland Papers, 1(6): 203-223, 1972.

RAIJ, B. van \& CAMARGO, O.A. de. Silica solúvel em solos. Bragantia, Campinas, $32(11)$ : 223-231, 1973.

RAIJ, B. van \& QUAGGIO, J.A. Mētodos de anālise de solos pa ra fins de fertilidade. Campinas, Instituto Agronōmico, 1983, 31p. (Bol. Técnico, 81). 
RAJAN, S.S.S. Phosphate adsorption and the displacement of structural silicon in an allophane clay. J. of Soil sci. 26: 250-256, 1975 .

RAJAN, S.S.S. \& FOX, R.L. Phosphate adsorption by soils. II. Reaction in tropical acid soils. Soil Sci. Soc. Amer. Proc., 39: 846-851, 1975.

RAJAN, S.S.S. \& PERROTT, K.W. Phosphate adsorption by synthetic amorphus aluminosilicates. J. Soil Sci., Oxford, 26(3) : 257-226, 1985...

RAJAN, S.S.S. \& WATKINSON, P.H. Adsorption of selenite and phosphate en a allophane clay. Soil Sci. Soc. Amer. J.. Madison, 40: 51-54, 1976.

RALEIGH, G.J. Some effects of various silicates, lime and gypsum on growth of tomato plants in Western and Eastern soils of low levels of phosphorus nutrition. Cornell Agric. Exp. Sta. Memo., 326: p.78, 1953.

RAUPACH, \& PIPER, C.S. Interections of silicate and phosphate in a lateritis soil. Aust. J. Agric. Res., Melbourne, 10: $813-831,1959$. 
REIFENBERG, A. \& BUCKWOLD, S.J. The release of silica from soils by the orthophosphate anions. J. Soil Sci., Oxford, $5(1): 106-115,1954.0$

RODRIGUES, T.E. Mineralogia e gênese de uma sequência de solos dos cerrados no Distrito Federal. 101 f. Tese. (Mes tr. Agron.-solos) Faculdade de Agronomia, UFRGS, Porto Alegre, 1977.

ROTHBUHR, \& SCOTT, F. A study of the uptake of silicon and phosphorus by wheat plants with radio chemical methods. Biochem. J., 65: 241-245, 1957.

ROY, A.C.; ALI, M.Y.; FOX, R.L. \& SILVA, J.A. Influence of calcium silicate on phosphate solubility and avaibilility in Havalian Latosols. In: Symposium on soil fertility e valuation, Honolulu, (proceedings), New Delhi, India, $1971,756-765$.

SCARSETH, G.D. The mechanism of phosphate retention by natu ral alumino silicate colloids. J... Amer. Soc.; 27: $596-616,1935$.

SHERMAN, G.D. Crop growth response applications of calcium silicate to tropical soils in Hawaiian Islands. Agricult. Digest., 18: 11-19, 1969. 
SILVA, N.M.; FERRAZ, C.A.M.; CAMPANA. M.P. Competição entre superfosfato simples e termofosfatos, em ensaio permanente com o algodoeiro. Revista Brasileira de Ciência do So 1o. Campinas, 1(1): 34-38, 1977.

SMITH, T.J. \& SNACHEZ, P.A. Effects of lime, silicate and phosphorus applications to an oxisol on phosphorus sorptions and ion retention. Soil Sci. Soc. Amer. J., 44: $500-505,1980$.

TAYLOR, A.W. Review of the effects of siliceous dressings on the nutrient status of soils. Agric. Food. Chem., 9: $163-165,1961$.

VOLKWEISS, S.J. \& RAIJ, B. Van. Retenção e disponibilidade de fósforo em solos, In: SIMPÓSIO SOBRE OS CERRADOS, 40, Brasilia, 21-25 de junho. Anais.... Ed. Itatiaia, 1976, $16 \mathrm{p}$.

YOSHIDA, S.; OHNYSHI, Y. \& KITAGUISHI, K. Histochemistry of silicon in rice plant. Soil Sci.. and Plant Nutr. $8(1): 30-35,1962$.

WAUGH, D.L. \& FITTS, J.W. Estudos para interpretação de aná lise de solo: de laboratório e em vasos. Raleigh, Interna tional Soil Testing. 1966, 33p. (Boletim Técnico no 3). 